\title{
NR2D-containing NMDA receptors mediate tissue plasminogen activator-promoted neuronal excitotoxicity
}

\author{
A Baron ${ }^{1,2}$, A Montagne $^{1,2}$, F Cassé $^{1,2}$, S Launay ${ }^{1,2}$, E Maubert $^{1,2}$, C Ali ${ }^{1,2}$ and D Vivien ${ }^{\star, 1,2}$
}

\begin{abstract}
Although the molecular bases of its actions remain debated, tissue-type plasminogen activator (tPA) is a paradoxical brain protease, as it favours some learning/memory processes, but increases excitotoxic neuronal death. Here, we show that, in cultured cortical neurons, tPA selectively promotes NR2D-containing $N$-methyl-D-aspartate receptor (NMDAR)-dependent activation. We show that IPA-mediated signalling and neurotoxicity through the NMDAR are blocked by co-application of an NR2D antagonist (phenanthrene derivative $\left(2 S^{*}, 3 R^{*}\right)$-1-(phenanthrene-2-carbonyl)piperazine-2,3-dicarboxylic acid, PPDA) or knockdown of neuronal NR2D expression. In sharp contrast with cortical neurons, hippocampal neurons do not exhibit NR2D both in vitro and in vivo and are consequently resistant to tPA-promoted NMDAR-mediated neurotoxicity. Moreover, we have shown that activation of synaptic NMDAR prevents further TPA-dependent NMDAR-mediated neurotoxicity and sensitivity to PPDA. This study shows that the earlier described pro-neurotoxic effect of tPA is mediated by NR2D-containing NMDARdependent extracellular signal-regulated kinase activation, a deleterious effect prevented by synaptic pre-activation. Cell Death and Differentiation (2010) 17, 860-871; doi:10.1038/cdd.2009.172; published online 13 November 2009
\end{abstract}

In the central nervous system, the ability to convert plasminogen to plasmin was the first proposed molecular mechanism of action of tissue-type plasminogen activator (tPA) for not only the control of fibrinolysis, but also of neuronal survival and plasticity. ${ }^{1-3}$ However, tPA not only activates plasminogen, but rather acts through several modalities ${ }^{4}$ by interacting with the low-density lipoproteinrelated receptor protein (LRP), ${ }^{5-8}$ annexin- $\mathrm{II}^{9}$ or $\mathrm{N}$-methyl-Daspartate receptors (NMDAR). ${ }^{1,10-12}$ These interactions mediate several potentially damaging effects of tPA, including potentiation of NMDAR-mediated signalling and excitotoxicity. ${ }^{6,7,10}$ During excitotoxic conditions, tPA has been shown to promote NMDA-induced calcium influx in cortical neurons and subsequent neuronal death through the binding to and cleavage of the NR1 subunit of the NMDAR, either directly ${ }^{10,11}$ or through the recruitment of LRP. ${ }^{7}$ The interaction between IPA and the NR1 subunit was shown in vivo to be involved in both excitotoxic and memory paradigms in mice. ${ }^{12}$ The intimate link between tPA and NMDAR is reinforced by other observations, such as the modulation of the phosphorylation state of the NR2B subunit of the NMDAR in conditions of chronic alcohol consumption and contextual fear conditioning $^{13,14}$ or the promotion of NMDAR-dependent extracellular signal-regulated kinase $\left(\operatorname{Erk}\left(\frac{1}{2}\right)\right)$ signalling in hippocampal neurons. ${ }^{6,15}$ Thus, there is now accumulating evidence that tPA must be considered as a positive neuromodulator of NMDAR-mediated glutamatergic transmission. ${ }^{11,16}$
NMDAR have a crucial function in brain development, plasticity and survival. ${ }^{17}$ Deregulations of these receptors can contribute to a variety of neurological and neurodegenerative disorders. ${ }^{18,19}$ NMDAR are mainly composed of assembled $\mathrm{NR} 1 \mathrm{a} / \mathrm{b}$ and heteromeric NR2 subunits, including NR2A, NR2B and NR2D. ${ }^{20}$ Both subunit composition and localization within the neuron (synaptic or extra-synaptic) ${ }^{21}$ and subunitspecific protein associations ${ }^{22}$ of NMDAR are key determinants of their signalling capacities and implications in the control of neuronal death and survival.

We evidence here that tPA promotes signalling and subsequent neurotoxicity through NR2D subunit-containing NMDAR. In addition, pre-stimulation of synaptic NMDAR prevents tPA-induced potentiation of NR2D-containing NMDAR-dependent $\operatorname{Erk}\left(\frac{1}{2}\right)$ activation and subsequent proneurotoxicity.

\section{Results}

tPA exacerbates neurotoxicity through NR2D-containing NMDAR. Erk $\left(\frac{1}{2}\right)$, a member of the mitogen-activated kinase (MAPK) family, was earlier reported to be recruited in response to NMDAR activation. ${ }^{15}$ We thus used phosphorylation of $\operatorname{Erk}\left(\frac{1}{2}\right)$ as an index of NMDAR-dependent signalling. Accordingly, in primary cultures of pure cortical neurons maintained either 7 days in vitro (DIV) (Supplementary Figure 1a and b) or 12-14 DIV (Supplementary

${ }^{1}$ INSERM, INSERM U919, Serine Proteases and Pathophysiology of the neurovascular Unit (SP2U), Cyceron, University of Caen Basse-Normandie, Caen Cedex F-14074, France and ${ }^{2}$ CNRS, UMR CNRS 6232 Ci-NAPs 'Center for imaging - Neurosciences and Application to Pathologies', Cyceron, Caen Cedex F-14074, France *Corresponding author: D Vivien, INSERM U919, Serine Proteases and Pathophysiology of the neurovascular Unit (SP2U), UMR CNRS 6232 Ci-NAPs 'Center of imaging - Neurosciences and Application to Pathologies', Bd H. Becquerel, BP 5229, Caen Cedex F-14074, France. Tel: + 33231470166 ; Fax: + 33231470222 ; E-mail: vivien@cyceron.fr

Keywords: NR2D; tPA; NMDA; excitotoxicity; pre-conditionning

Abbreviations: 4-AP, 4-aminopyridin; Erk $\left(\frac{1}{2}\right)$, extracellular signal-regulated kinase; LRP, low-density lipoprotein-related receptor protein; NMDAR, N-methyl-Daspartate receptor; PPDA, phenanthrene derivative $\left(2 S^{*}, 3 R^{*}\right)$-1-(phenanthrene-2-carbonyl)piperazine-2,3-dicarboxylic acid; tPA, tissue-type plasminogen activator Received 01.5.09; revised 07.10.09; accepted 07.10.09; Edited by V De Laurenzi; published online 13.11.09 


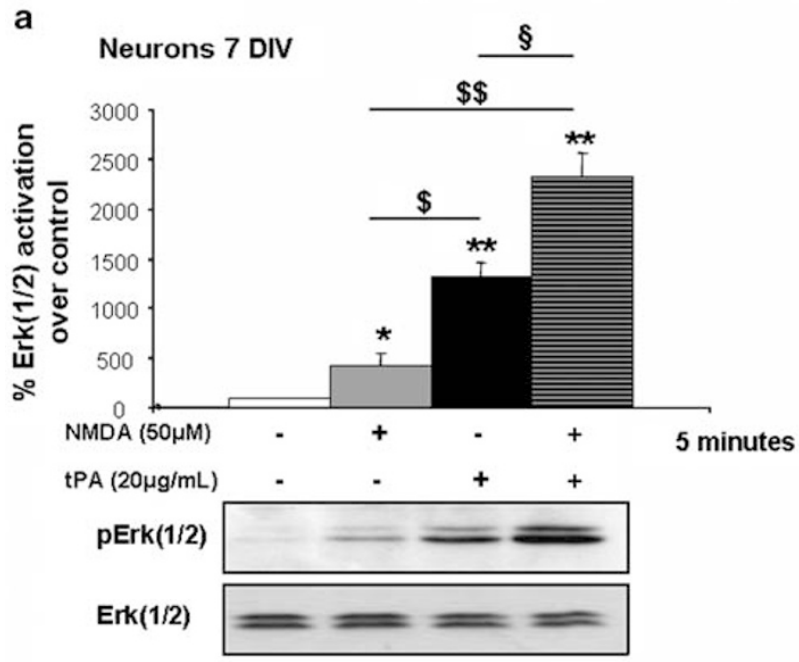

C

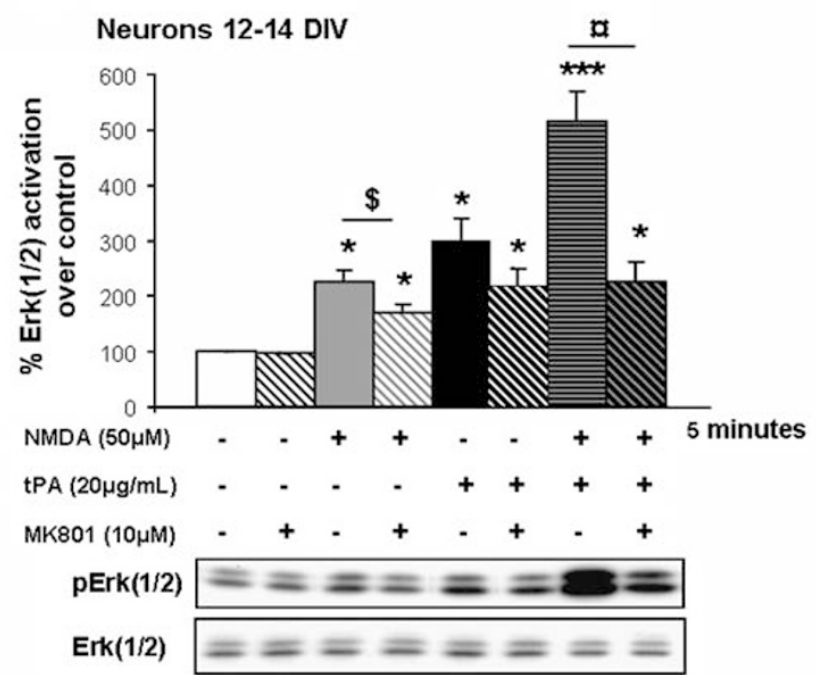

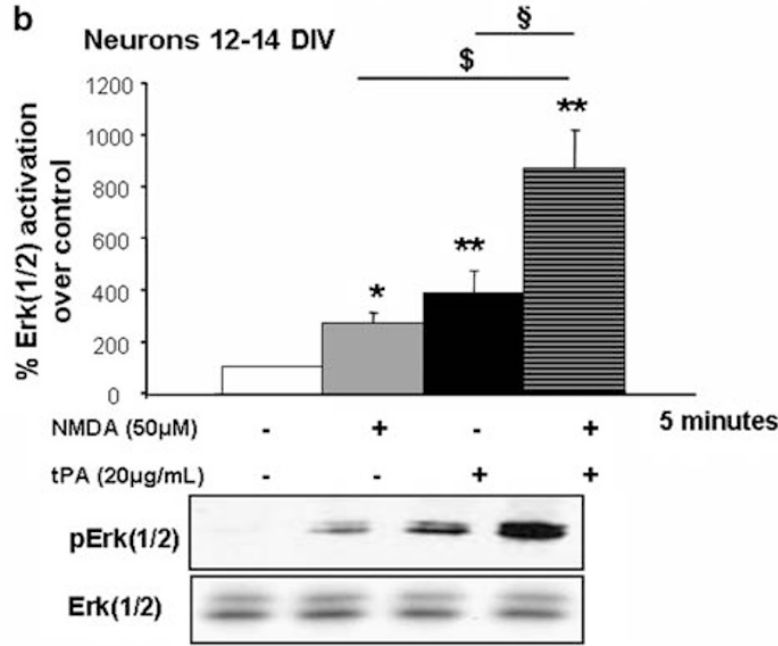

d Neurons 12-14 DIV

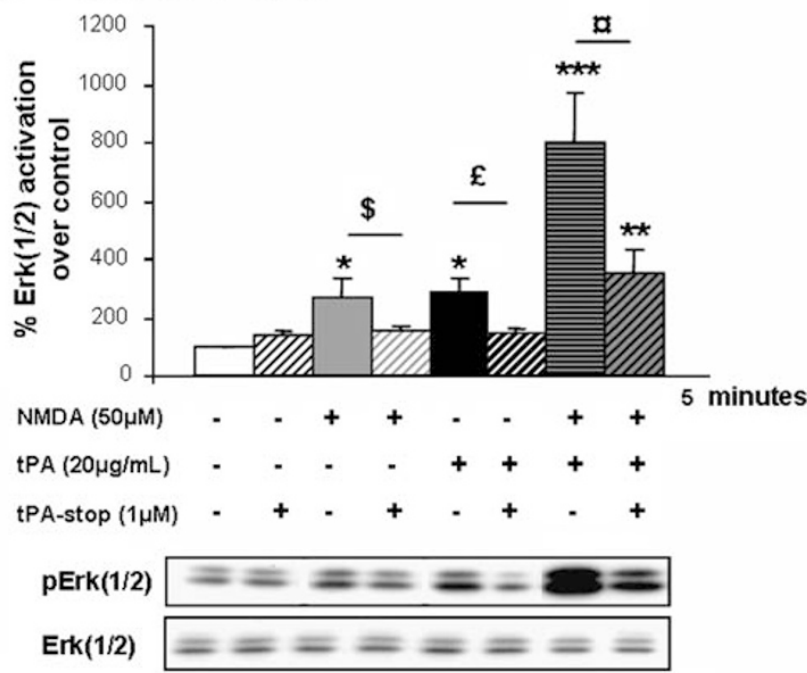

Figure 1 Catalytic tPA promotes NMDAR-induced Erk $\left(\frac{1}{2}\right)$ MAPK activation $(\mathbf{a}, \mathbf{b})$. Immunodetection of activated and total Erk $\left(\frac{1}{2}\right)$ performed after 5 min of treatment of cortical neurons (7 DIV for a; $12-14$ DIV for b) with NMDA $(50 \mu \mathrm{M})$, tPA $(20 \mu \mathrm{g} / \mathrm{ml})$ or NMDA $(50 \mu \mathrm{M})+\operatorname{tPA}(20 \mu \mathrm{g} / \mathrm{ml})$. The graphs show the quantification of Erk $\left(\frac{1}{2}\right)$ activation. Data are represented as mean \pm S.E.M. $(N=8 ; n=24)$ relative to control $\left({ }^{*, \$, \$} P<0.05 ;{ }^{* *, \$ \$} P<0.01\right)$. ${ }^{*}$ Indicates significantly different from control; ${ }^{\$}$ indicates significantly

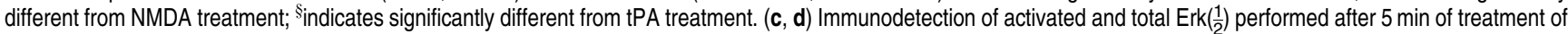
cortical neurons (12-14 DIV) with NMDA $(50 \mu \mathrm{M})$, tPA $(20 \mu \mathrm{g} / \mathrm{ml})$ or NMDA $(50 \mu \mathrm{M})+\operatorname{tPA}(20 \mu \mathrm{g} / \mathrm{ml}) \pm$ MK-801 $(10 \mu \mathrm{M})(\mathbf{c})$ or \pm tPA-stop $(1 \mu \mathrm{M})(\mathrm{d})$. The graphs show the quantification of Erk $\left(\frac{1}{2}\right)$ activation. Data are represented as mean \pm S.E.M. $(N=4 ; n=12)$ relative to control $\left({ }^{*, \$, £, \not a} P<0.05 ;{ }^{\star *} P<0.01 ;{ }^{* \star \star} P<0.001\right)$. ${ }^{*}$ Indicates significantly

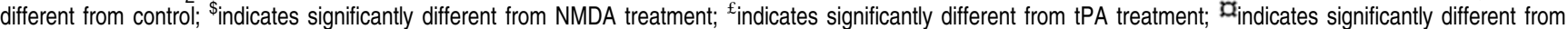
NMDA + tPA treatment

Figure 1c and d), we observed that NMDA $(50 \mu \mathrm{M})$ induced a rapid and transient activation of Erk $\left(\frac{1}{2}\right)$ within $5 \mathrm{~min}$, an effect which disappeared as early as after 15 min (Supplementary Figure $1 \mathrm{~b}-\mathrm{d})$. This activation of $\operatorname{Erk}\left(\frac{1}{2}\right)$ after 5 min of NMDA exposure was strongly potentiated by tPA (Figure 1a and $b$ ). In the presence of MK-801 $(10 \mu \mathrm{M})$, an NMDAR-channel blocker with high affinity and a very slow off rate, $\operatorname{Erk}\left(\frac{1}{2}\right)$ activation induced by NMDA alone, or NMDA plus IPA $(20 \mu \mathrm{g} / \mathrm{ml})$ was dramatically reduced in neurons maintained for $12-14$ DIV (Figure 1C), arguing that Erk $\left(\frac{1}{2}\right)$ activation is dependent on NMDAR activation. IPA alone also led to an increased activation of $\operatorname{Erk}\left(\frac{1}{2}\right)$, which was not blocked by the addition of MK-801 (10 $\mu \mathrm{M})$ (Figure 1c), suggesting as shown earlier ${ }^{15}$ that tPA could mediate some of its effects through other receptors.

The serine protease activity of TPA has been shown to be necessary to influence NMDAR-induced calcium influx. ${ }^{10,11}$ To determine whether this is also the case for NMDA-induced $\operatorname{Erk}\left(\frac{1}{2}\right)$ phosphorylation, neurons were treated with tPA-stop $(1 \mu \mathrm{M})$, a synthetic inhibitor of the proteolytic activity of tPA. Exogenously added tPA or released endogenous TPA because of treatment with $\mathrm{NMDA}^{10}$ both led to increased $\operatorname{Erk}\left(\frac{1}{2}\right)$ phosphorylation, and in both cases, addition of tPAstop caused a significant reversal effect (Figure 1d). A proteolytic event is thus necessary for IPA-induced potentiation of NMDAR-induced $\operatorname{Erk}\left(\frac{1}{2}\right)$ activation. 
a
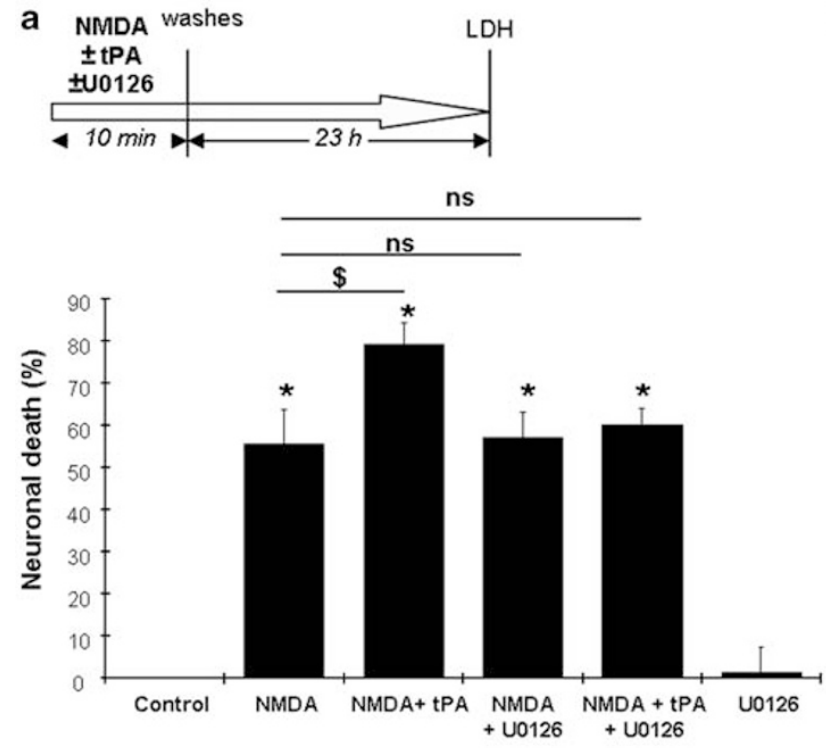

b
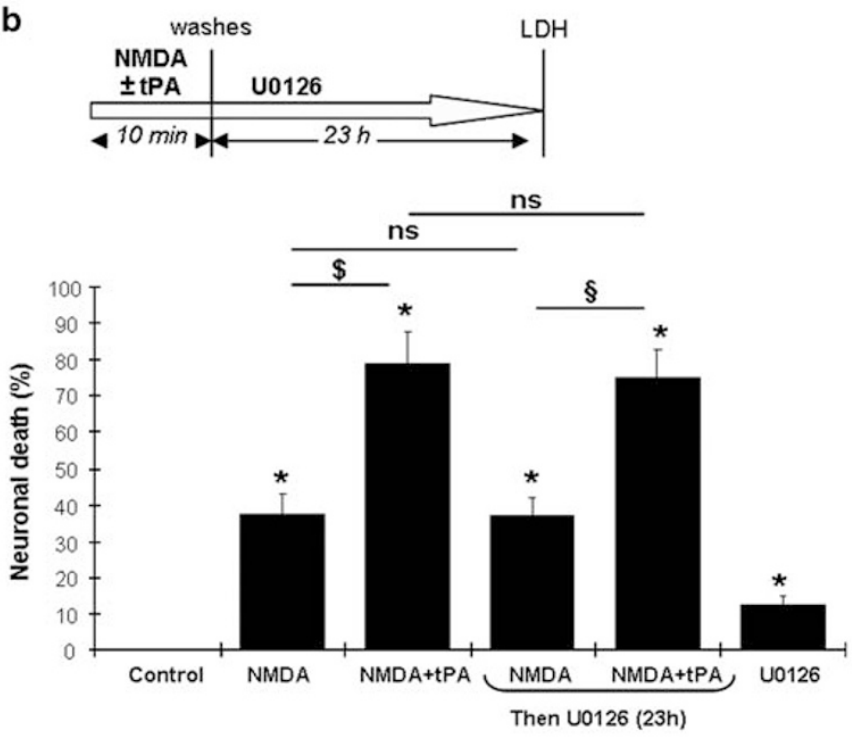
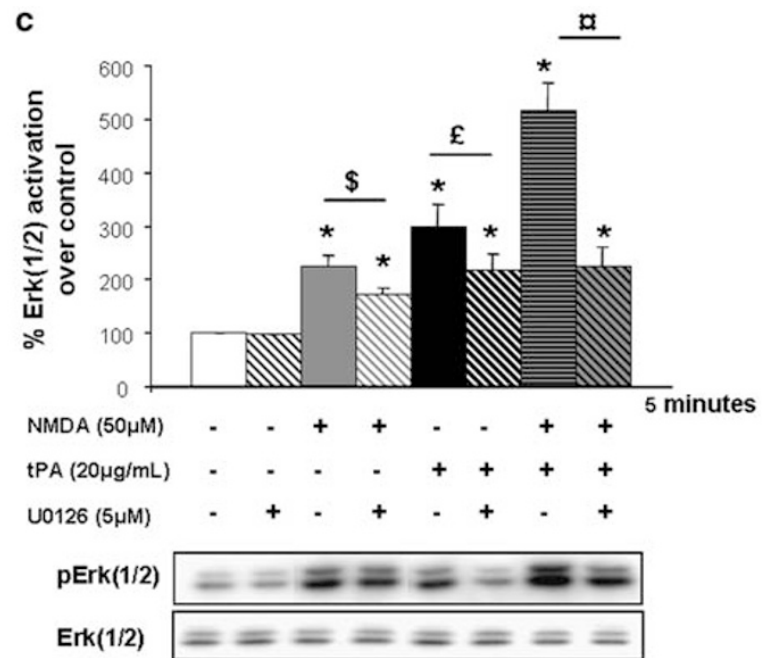

Figure 2 Important function of Erk $\left(\frac{1}{2}\right)$ MAPK activation in the pro-excitotoxic effect of tPA. Neurons (12-14 DIV) were exposed (a) for 10 min to NMDA (50 $\mu$ M) \pm tPA $(20 \mu \mathrm{g} / \mathrm{ml}) \pm$. U0126 $(5 \mu \mathrm{M})$, or $(\mathbf{b})$ for $10 \mathrm{~min}$ to NMDA $(50 \mu \mathrm{M}) \pm \mathrm{tPA}(20 \mu \mathrm{g} / \mathrm{ml})$ and then $\mathrm{U} 0126$ was added after washes during the last $23 \mathrm{~h} 50 \mathrm{~min}$. LDH released into the bathing medium was assessed $24 \mathrm{~h}$ after the beginning of the excitotoxic exposure. Data are represented as mean \pm S.E.M. $(N=4 ; n=16)$ relative to control $(*, \$, \$<0.05)$.

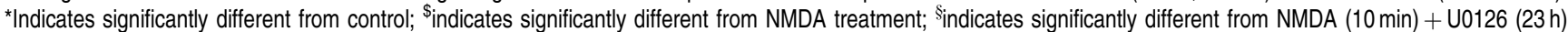
treatment. (ns: not significant). (c) Immunodetection of activated and total Erk $\left(\frac{1}{2}\right)$ performed after 5 min of treatment of cortical neurons (12-14 DIV) in the presence of NMDA $(50 \mu \mathrm{M})$, tPA $(20 \mu \mathrm{g} / \mathrm{ml})$ or NMDA $(50 \mu \mathrm{M})+$ tPA $(20 \mu \mathrm{g} / \mathrm{ml}) \pm$ U0126 $(5 \mu \mathrm{M})$. The graph shows the quantification of Erk $\left(\frac{1}{2}\right)$ activation. Data are represented as mean \pm S.E.M.

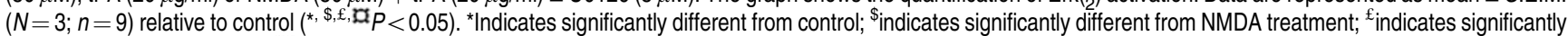

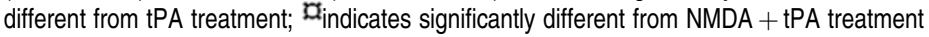

In agreement with the earlier shown aggravating effect of tPA on slowly triggered NMDA toxicity, ${ }^{10}$ we observed that a co-application of tPA $(20 \mu \mathrm{g} / \mathrm{ml})$ during a short exposure (10 min) to a high concentration of NMDA $(50 \mu \mathrm{M})$ in 12-14 DIV neuronal cultures increased neuronal death measured $24 \mathrm{~h}$ later (Figure 2a). To investigate the possible involvement of early $\operatorname{Erk}\left(\frac{1}{2}\right)$ MAPK activation in this tPA-induced potentiation of NMDAR-mediated neurotoxicity, a co-application of tPA and/or U0126 $(5 \mu \mathrm{M})$, the upstream MAPK kinase $\left(\operatorname{MEK}\left(\frac{1}{2}\right)\right)$ inhibitor, was performed during the $10 \mathrm{~min}$ exposure of neurons to NMDA and neuronal death was measured at $24 \mathrm{~h}$. In such conditions, the blockage of $\operatorname{Erk}\left(\frac{1}{2}\right)$ MAPK completely prevented the pro-excitotoxic effect of tPA (Figure 2a) with no effect on NMDA-mediated neuronal death when applied alone. In contrast, when added after this period of 10 min of NMDA/tPA co-treatment, U0126 did not prevent tPA-induced potentiation of NMDA-mediated neurotoxicity (Figure $2 b$ ). These data confirm that early $\operatorname{Erk}\left(\frac{1}{2}\right)$ MAPK activation induced by IPA in the presence of NMDA mediates the pro-neurotoxic effects of tPA. U0126 was also associated with the prevention of the ability of TPA to promote NMDARdependent activation of $\operatorname{Erk}\left(\frac{1}{2}\right)$ signalling (Figure 2c).

Then, the possible involvement of LRP in NMDAR-tPA interaction was investigated by using receptor-associated 


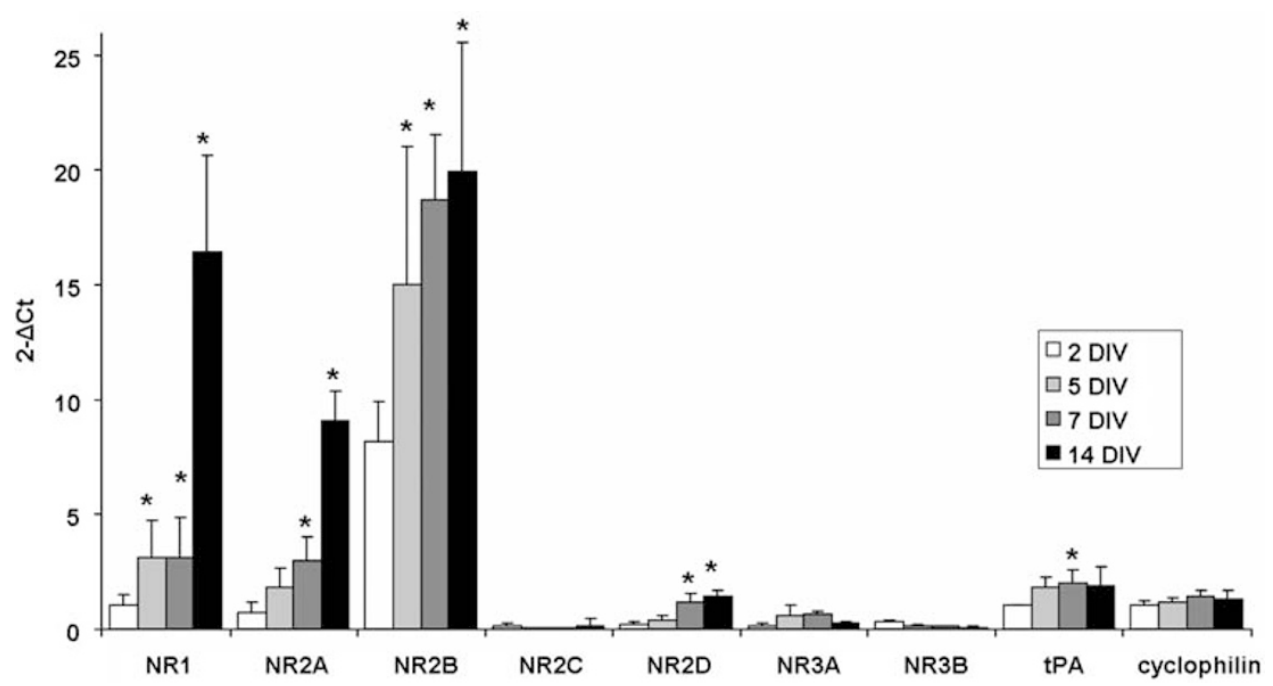

Figure 3 Characterization of tPA and NR2D expression. mRNA levels of NMDAR subunits (NR1, NR2 and NR3) and tPA in cultured neurons at 2, 5, 7 and 14 DIV ( $N=3$, $n=9)$. The results of relative levels of mRNA expression were computed by calculating the $2-\Delta C t$ and are represented by mean \pm S.D. *Indicates significantly different from the 2 DIV value $(P<0.05)$. The house keeping gene expression (cyclophilin) was not influenced by the stage in vitro

protein (RAP), a competitive antagonist of LRP. Treatment with RAP failed to influence both Erk $\left(\frac{1}{2}\right)$ signalling induced by application of tPA and/or NMDA (Supplementary Figure 2a) and the ability of tPA to promote NMDA-induced neuronal death (Supplementary Figure $2 b$ ), ruling out any involvement of LRP on the observed effects of tPA.

When characterizing the temporal profile of NMDAR subunits expression according to the maturation state of primary cultures of cortical neurons (2 to $14 \mathrm{DIV}$ ), we found, in addition to an up-regulation of NR1 and NR2A expression during neuronal maturation in vitro, a significant overexpression of NR2D subunit (Figure 3). The expression levels of NR2C mRNA were low, whatever the stage investigated may be. A confocal microscopy analysis confirmed the presence of an NR2D and NR1 positive immunostaining at the neuronal membrane (see Figure $8 \mathrm{~b}$ ). We postulated that NR2D could have a critical function in the ability of tPA to promote NMDAR-mediated neurotoxicity. To address this question, we took advantage of the absence of NR2C subunits in our cell culture system (Figure 3) and used phenanthrene derivative $\left(2 S^{*}, 3 R^{*}\right)-1$-(phenanthrene-2carbonyl)piperazine-2,3-dicarboxylic acid (PPDA) at a concentration of $0.2 \mu \mathrm{M}$, earlier reported to inhibit NR2Dcontaining NMDAR. ${ }^{23,24}$ In the presence of PPDA, the deleterious effect of TPA on NMDA-induced neuronal death was completely prevented (Figure 4a), supporting the actual involvement of NR2D-containing NMDAR. To further validate the hypothesis that NR2D subunit has an important function in NMDAR-mediated neurotoxicity, primary cultures of cortical neurons (12-14 DIV) were transiently transfected with Stealth RNA interference targeting NR2D. Among three tested smallinterfering RNAs (siRNAs), we selected one (GRIN2D 23) reducing NR2D mRNA expression by $40 \%$ (Figure $4 \mathrm{~b}$ ) and having no effect on mRNA levels for the other NMDAR subunits (NR1, NR2A, NR2B, NR2C, NR3A, NR3B) (data not shown). We found that the knockdown of neuronal NR2D expression had no effect on basal NMDA-induced neuronal death, but prevented the potentiating effect of tPA (Figure 4c). Accordingly, NR2D RNA interference prevented tPA-promoted NMDAR-induced Erk $\left(\frac{1}{2}\right)$ signalling (Figure 4d).

Interestingly, we observed a difference of sensitivity of neurons to the pro-excitotoxic effect of TPA according to their brain structure of origin. Indeed, although tPA was able to potentiate NMDA-dependent neuronal death in cortical cultures (Figure 5A), it failed to do so in hippocampal neurons (Figure 5B). RT-qPCR (Figure 5C), immunocytochemistry and immunohistochemistry (Figure 5D) revealed that while the NR2D subunit is clearly expressed in cortical neurons, it is barely detectable in hippocampal neurons of CA1, CA3 and gyrus dentate areas. Of note, neurons of CA2 exhibit NR2D. On the basis of these observations, we compared the sensitivity of these two brain structures to an intravenous administration of tPA $(10 \mathrm{mg} / \mathrm{ml})$ during an NMDA-induced excitotoxic challenge. As expected, although tPA promoted NMDA-induced cortical injury (Figure 5E and F), it had no effect on the lesion induced by NMDA in the hippocampus (Figure $5 \mathrm{G}$ and $\mathrm{H}$ ). Altogether these data show that NR2D has an important function in tPA-promoted excitotoxicity, which might be of significant relevance for several neurodegenerative disorders, including ischemic brain injury.

Priming of synaptic NMDAR prevents tPA-promoted NMDAR signalling and neurotoxicity. The neurotoxic effects of NMDA at a concentration of $50 \mu \mathrm{M}$ are thought to be mainly attributable to extra-synaptic NMDAR. ${ }^{25}$ Accordingly, we sought to determine whether the synaptic NMDAR have any implication in the potentiation of NMDAdependent signalling and death by tPA. Synaptic NMDAR were specifically activated by application of a combination of bicuculline (a GABA-A inhibitor; $50 \mu \mathrm{M}$ ) and 4-aminopyridin (4-AP, a weak potassium-channel blocker; $2.5 \mathrm{mM}$ ) as described earlier. ${ }^{25,26}$ Although bicuculline-induced $\operatorname{Erk}\left(\frac{1}{2}\right)$ phosphorylation was prevented by MK-801 (Figure 6a), exogenous tPA failed to influence $\operatorname{Erk}\left(\frac{1}{2}\right)$ signalling after 


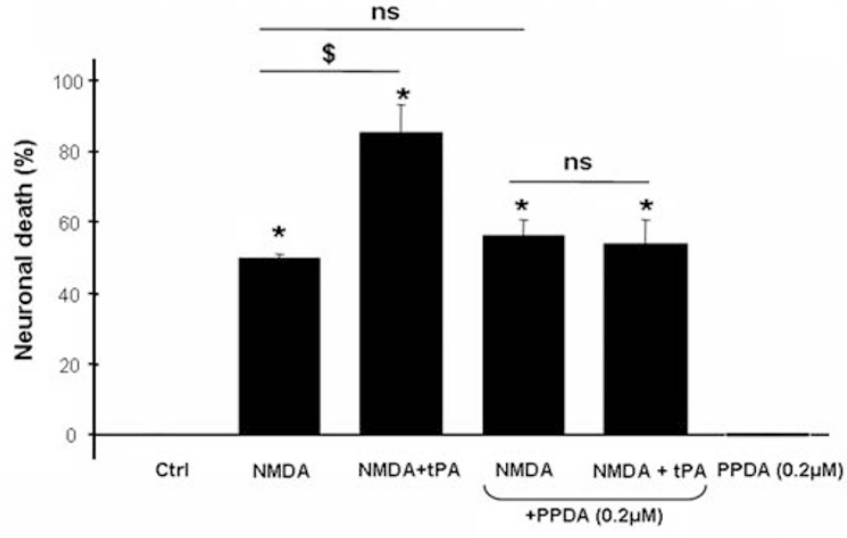

b

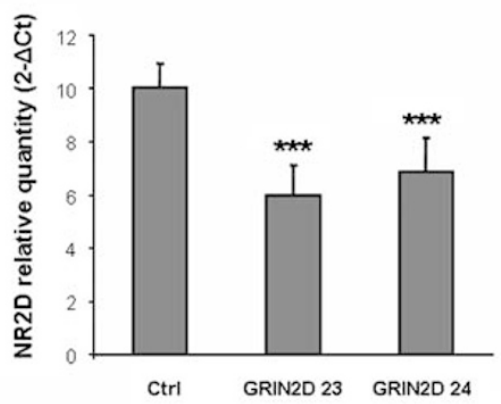

d Neurons 12-13 DIV transfected with siRNA NR2D

C

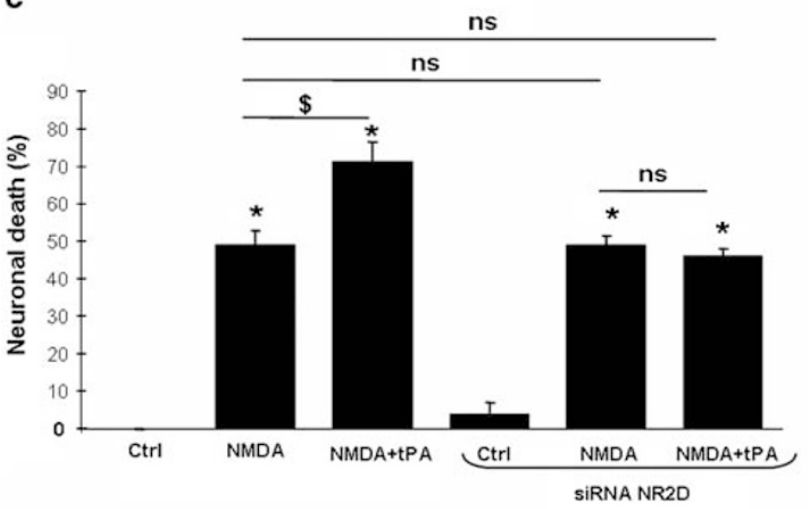

\$

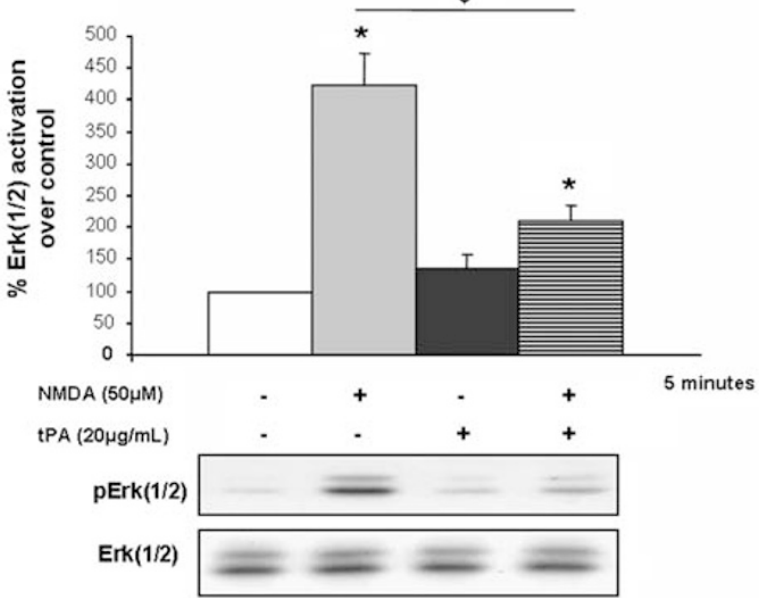

Figure 4 The tPA promotes NR2D-containing NMDAR signalling and neurotoxicity (a) Neurons (12-14 DIV) were exposed for $60 \mathrm{~min}$ to NMDA (50 $\mu \mathrm{M}) \pm \mathrm{tPA}(20 \mu \mathrm{g} / \mathrm{ml})$. PPDA $(0.2 \mu \mathrm{M})$ was added concurrently with NMDA to block NR2D-containing NMDAR. LDH released into the bathing medium was assessed $24 \mathrm{~h}$ after the excitotoxic exposure. Data are represented as mean \pm S.E.M. $(N=3 ; n=12)$ relative to control $(*, \$<<0.05)$. ${ }^{*}$ Indicates significantly different from control; ${ }^{\$}$ indicates significantly different from NMDA treatment; ns: not significant. (b) mRNA levels of NR2D NMDAR subunits in cultured neurons at 12-13 DIV $(N=3 ; n=18)$ were evaluated after transient transfection of neurons with either siRNA GRIN2D 23 or siRNA GRIN2D 24, respectively. Relative levels of mRNA expression were measured by quantitative PCR. The results were computed in relative quantity $\left(2^{-\Delta C t}\right)$. The graph represents mean values \pm S.D. *Indicates significantly different from the control value $\left(^{\star \star \star} P<0.001\right)$. (c) Neurons (12-14 DIV) transfected or not with siRNA GRIN2D 23 were exposed for $60 \mathrm{~min}$ to NMDA $(50 \mu \mathrm{M})$ alone or in the presence of tPA (20 $\mu \mathrm{g} / \mathrm{ml})$. LDH released into the bathing medium was assessed $24 \mathrm{~h}$ after the excitotoxic exposure. (d) Immunodetection of activated and total Erk $\left(\frac{1}{2}\right)$ performed after either 5 min of treatment of siRNA GRIN2D 23 transfected neurons (12-3 DIV) in the presence of NMDA $(50 \mu \mathrm{M})$, tPA $(20 \mu \mathrm{g} / \mathrm{ml})$ and NMDA $(50 \mu \mathrm{M})+\operatorname{tPA}(20 \mu \mathrm{g} / \mathrm{ml})$. The graph shows the quantification of Erk $\left(\frac{1}{2}\right)$ activation in the same conditions as described in (c). For (c, d), data are represented as mean \pm S.E.M. ((c) $N=3 ; n=12 ;(\mathbf{d}) N=4 ; n=12)$ relative to control $(*, \$ P<0.05)$. *Indicates significantly different from control; ${ }^{\$}$ indicates significantly different from NMDA treatment; ns: not significant

bicuculline +4-AP exposure in neurons maintained for 12-14 DIV (Figure 6b).

On the basis of these observations, this paradigm was used as a protocol of synaptic preconditioning before NMDA application. Neurons were first treated with bicuculline $+4-\mathrm{AP}$, followed by addition of MK-801 $(10 \mu \mathrm{M})$ and subsequent application of NMDA $(50 \mu \mathrm{M})$ alone or with tPA. Interestingly, in such conditions, while the rapid and transient NMDARinduced activation of $\operatorname{Erk}\left(\frac{1}{2}\right)$ (at $5 \mathrm{~min}$ ) was not affected, tPA was no longer able to potentiate it (Figure $6 c$ and $d$ ). These data show that prior stimulation of synaptic NMDAR could prevent potentiation of NMDAR-dependent Erk $\left(\frac{1}{2}\right)$ signalling by tPA. Accordingly, we observed that, although pre-stimulation and then blockage of synaptic NMDAR did not affect subsequent NMDAR-induced neurotoxicity (around $40 \%$ of neuronal death similar to what was observed after regular application of NMDA), they prevented the ability of tPA to potentiate NMDA-dependent neurotoxicity (Figure 7a). To rule out a potential effect mediated by a direct bicucullinedependent activation of $\mathrm{GABA}_{\mathrm{A}}$ receptors, additional experiments were performed by using $\mathrm{KCl}$-induced depolarization to stimulate synaptic NMDAR before their blockage by MK-801. Consistent with our earlier observations, although tPA promoted NMDA-induced excitotoxicity, it had no effect when NMDA exposure was preceded by a priming of synaptic NMDAR (Figure 7b). Then, the same experiments were performed without blocking synaptic NMDAR by MK-801. As described above, while the pre-stimulation of synaptic NMDAR (by bicuculline + 4-AP or $\mathrm{KCl}$ ) did not affect NMDAdependent neurotoxicity, it prevented the pro-excitotoxic 
A
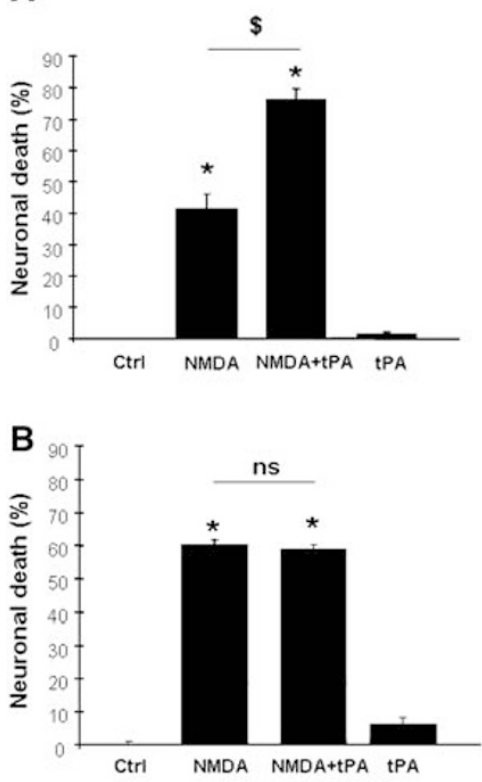

C

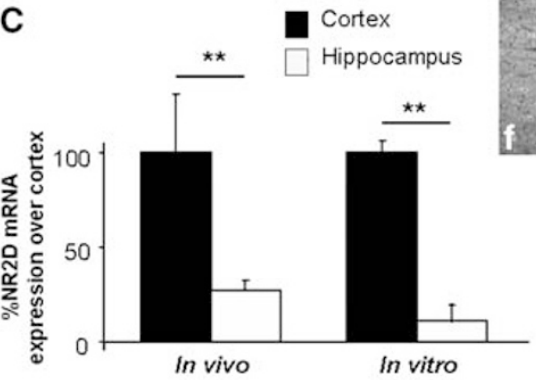

D

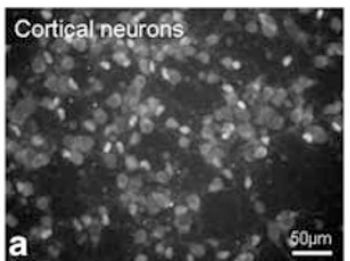

Hippocampal neurons
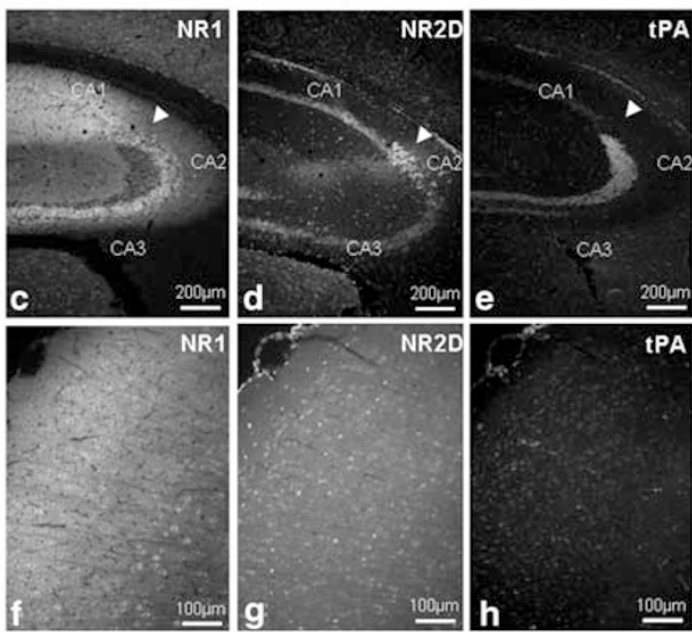

E

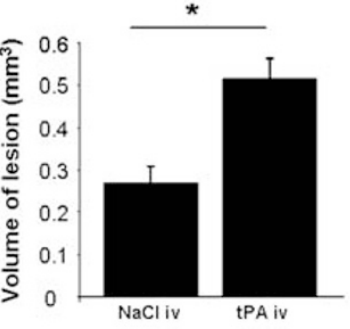

F
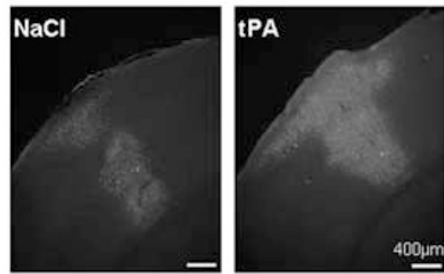

G

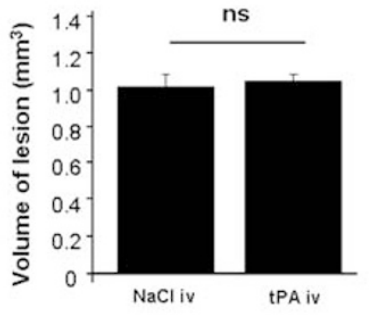

$\mathrm{H}$
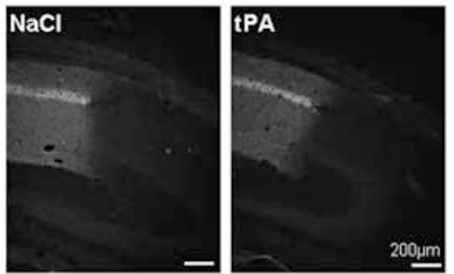

Figure 5 tPA fails to potentiate excitotoxicity of hippocampal neurons lacking NR2D. (A) Cortical neurons (12-14 DIV) or (B) hippocampal neurons (12-14 DIV) were exposed for $60 \mathrm{~min}$ to NMDA $(50 \mu \mathrm{M}) \pm \mathrm{tPA}(20 \mu \mathrm{g} / \mathrm{ml})$. LDH released into the bathing medium was assessed $24 \mathrm{~h}$ after the excitotoxic exposure. Data are represented as mean \pm S.E.M. $(N=3 ; n=12)$ relative to control $\left({ }^{*}{ }^{\$} P<0.05\right)$. *Indicates significantly different from control; ${ }^{\$}$ indicates significantly different from NMDA treatment; $n s:$ not significant $(N=6, n=6)$. (C) mRNA levels of NR2D subunit in cortical or hippocampal extracts and in cultured cortical or hippocampal neurons (14 DIV). The results of relative levels of mRNA expression (\%) were expressed over the cortical expression. ${ }^{*}$ Indicates significantly different from the cortical value $(P<0.01)$. (D) Immunostaining for NR2D (green) performed on primary cultures of mouse cortical (a) or hippocampal (b) neurons. (c-h) Immunostaining for NR2D (green) (c, d, f, g) and tPA (red) (e-h) performed from hippocampus (c-e) and cortex (f-h). DAPI staining is in blue. Scale bars represent $50 \mu \mathrm{m}$ for $(\mathbf{a}, \mathbf{b}), 200 \mu \mathrm{m}$ for $(\mathbf{c}-\mathbf{h})$. NMDA (2.5 nmoles) was injected either in the cortex $(\mathbf{E}, \mathbf{F})$ or in the hippocampus ( 5 nmoles) $(\mathbf{G}, \mathbf{H})$ with or not intravenous injection of tPA $(10 \mathrm{mg} / \mathrm{kg}) ; 24 \mathrm{~h}$ later lesions were stained with Fluoro-Jade $\mathrm{C}(\mathbf{F}-\mathbf{H})$ and an image analysis system was used to measure the lesioned area ( $(\mathbf{E})$ cortex; $(\mathbf{H})$ hippocampus). Scale bars represent $400 \mu \mathrm{m}$ for cortex $(\mathbf{F})$ and $200 \mu \mathrm{m}$ for hippocampus $(\mathbf{H})$. Data are represented as mean \pm S.E.M. ( $N=4$ for cortex, $N=5$ for hippocampus) relative to control ( $\left.{ }^{*} P<0.05\right)$. ${ }^{*}$ ndicates significantly different from $\mathrm{NaCl}(\mathrm{iv})$ treatment; $\mathrm{ns}$ : non significant (The colour reproduction of this figure is available on the html full text version of the manuscript)

effect of tPA (Figure 7c and d). Thus, pre-stimulation of synaptic NMDAR prevents potentiation of NMDA-induced signalling and neurotoxicity by tPA. Interestingly, PPDA (used at $1 \mu \mathrm{M}$, a concentration leading to a reduced NMDA-dependent neurotoxicity) did not influence NMDA-mediated neurotoxicity after a pre-synaptic priming $(\mathrm{KCl}$ stimulation as described above) (Figure 8a). Accordingly, immunocytochemistry for NR2D performed in primary cultures of cortical neurons showed that synaptic stimulation induced either by a $1 \mathrm{~h}$ exposure to bicuculline +4 -AP or a $15 \mathrm{~min}$ application of $\mathrm{KCl}$ led to a reduction of NR2D subunits available at the neuronal surface ( $\sim 65$ and $\sim 50 \%$, respectively) compared with the levels of NR1, which were not modified (Figure 8b and d).

These data suggest that a pre-stimulation of synaptic NMDAR probably leads to a critical change in the distribution of the NR2D-containing NMDAR that prevents NMDAmediated neurotoxicity and potentiation by IPA.

\section{Discussion}

It is now well admitted that NMDAR differentially control neuronal outcome depending on either their cellular localization ${ }^{26}$ and/or their composition in subunit ${ }^{27}$ and/or their anchorage with cytoplasmic or membrane-associated proteins. ${ }^{22}$

In this study, we first show that NMDAR-dependent $\operatorname{Erk}\left(\frac{1}{2}\right)$ activation is potentiated by both exogenous and endogenous tPA and that its catalytic activity of TPA is a necessary event. These data are in agreement with earlier reports, showing that the proteolytic activity of IPA is critical to mediate its 

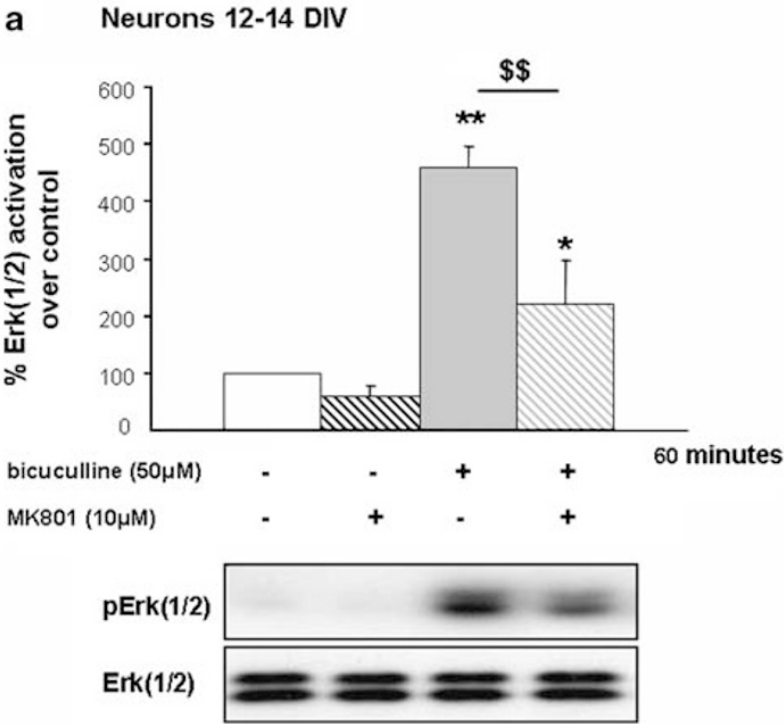

C Pre-treatment with bicuculline+4-AP and MK801

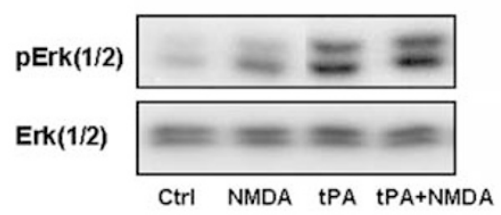

b Neurons 12-14 DIV

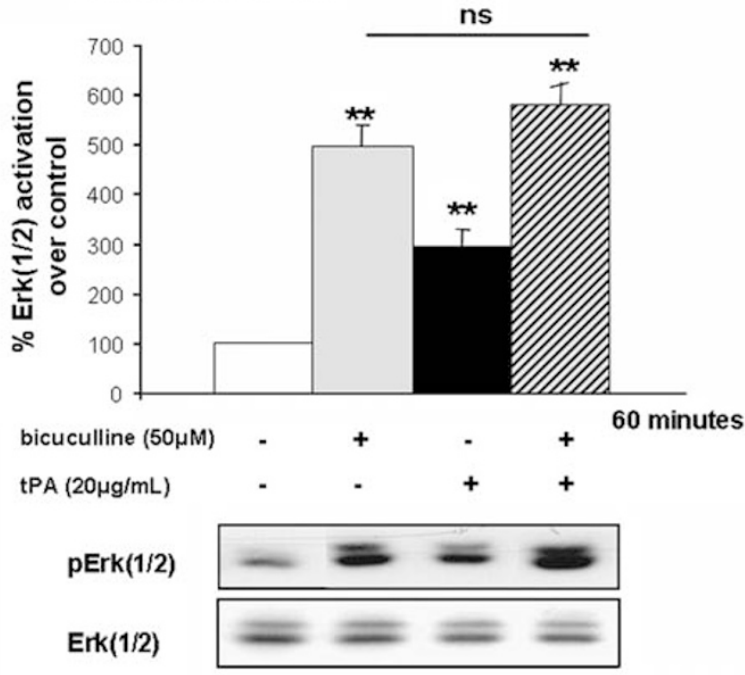

d Pre-treatment with bicuculline+4-AP and MK801

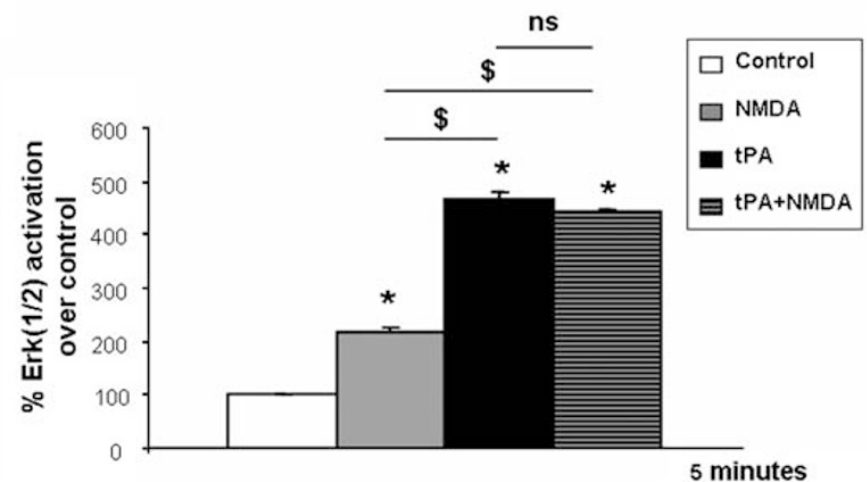

Figure 6 Synaptic pre-stimulation prevents tPA-promoted NMDAR signalling. (a) Immunodetection of activated and total Erk $\left(\frac{1}{2}\right)$ performed after $1 \mathrm{~h}$ of treatment of cortical neurons (12-14 DIV) with bicuculline $(50 \mu \mathrm{M})+4-\mathrm{AP}(2.5 \mathrm{mM}), \pm \mathrm{MK}-801(10 \mu \mathrm{M})$. The graph shows the quantification of Erk $\left(\frac{1}{2}\right)$ activation. (b) Immunodetection of activated and total Erk $\left(\frac{1}{2}\right)$ performed after $1 \mathrm{~h}$ of treatment of cortical neurons (12-14 DIV) with bicuculline $(50 \mu \mathrm{M})+4-\mathrm{AP}(2.5 \mathrm{mM})$, tPA $(20 \mu \mathrm{g} / \mathrm{ml})$ or bicuculline $(50 \mu \mathrm{M})+4-\mathrm{AP}$ $(2.5 \mathrm{mM})+\mathrm{tPA}(20 \mu \mathrm{g} / \mathrm{ml})$. The graph shows the quantification of Erk $\left(\frac{1}{2}\right)$ activation. Data are represented as mean \pm S.E.M. $(N=4 ; n=12)$ relative to control $\left({ }^{\star} P<0.05\right.$; $\left.{ }_{* *, \$ \$} P<0.01\right)$. (a, b) ${ }^{*}$ indicates significantly different from control; ${ }^{\$}$ indicates significantly different from bicuculline +4 -AP treatment; ns: not significant. (c) Immunodetection of activated and total Erk $\left(\frac{1}{2}\right)$ performed after 5 min of cortical neurons (12-14 DIV) with NMDA (50 $\left.\mu \mathrm{M}\right)$, tPA (20 $\left.\mu \mathrm{g} / \mathrm{ml}\right)$ or NMDA + tPA after priming. (d) The graph shows the quantification of Erk $\left(\frac{1}{2}\right)$ activation. Data are represented as mean \pm S.E.M. $(N=4 ; n=12)$ relative to control $\left({ }^{*} \$ P<0.05\right)$. *Indicates significantly different from control; $\$$ indicates significantly different from NMDA treatment; ns: not significant

pro-neurotoxic effects. ${ }^{7,10,11}$ In contrast, others have shown that tPA promotes NMDA-induced Erk $\left(\frac{1}{2}\right)$ signalling in hippocampal neurons independently of its proteolytic activity. ${ }^{15}$ Whether differences in maturity and/or brain structure of origin can explain this discrepancy remains to be defined. This data did not indicate an involvement of LRP in this mechanism. A recent report ${ }^{6}$ suggests that $\mathrm{tPA}$ could promote NMDAR signalling through an earlier recruitment of LPR-1 and a possible post-synaptic density-95 (PSD-95)-dependent interaction of TPA bound-LRP-1 with the NR1 subunit of the NMDAR. Surprisingly, although the TPA-induced potentiation of NMDAR signalling was extensively reported, neither co-application of tPA and NMDA were performed nor were neurotoxicity assays performed by these authors. Hence, we cannot exclude that in physiological conditions, a participation of LRP could occur, a mechanism that could be bypassed in pathological conditions, which cause overactivation of NMDAR. Moreover, in an earlier work, ${ }^{11}$ LRP has been described to be involved in the reuptake of tPA by astrocytes, suggesting a possible interference of LRP-dependent mechanism in cultured neurons-containing astrocytes. ${ }^{7}$ In this study, the primary cultures of neurons used contain $<5 \%$ of astrocytes.

Differential action of tPA could be also explained by variation in subunit composition of NMDAR. Indeed, NR2Aor NR2B-containing NMDAR within neurons and/or subunitspecific binding partners have been associated with possible differential signalling pathways including neurotoxicity and survival. However, determination of the relative distribution of different NMDAR populations in tPA effects remained a matter 
a

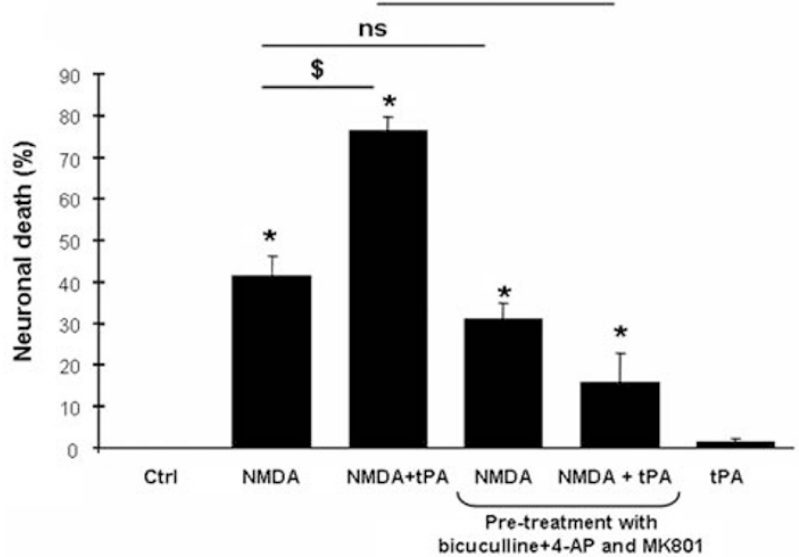

C

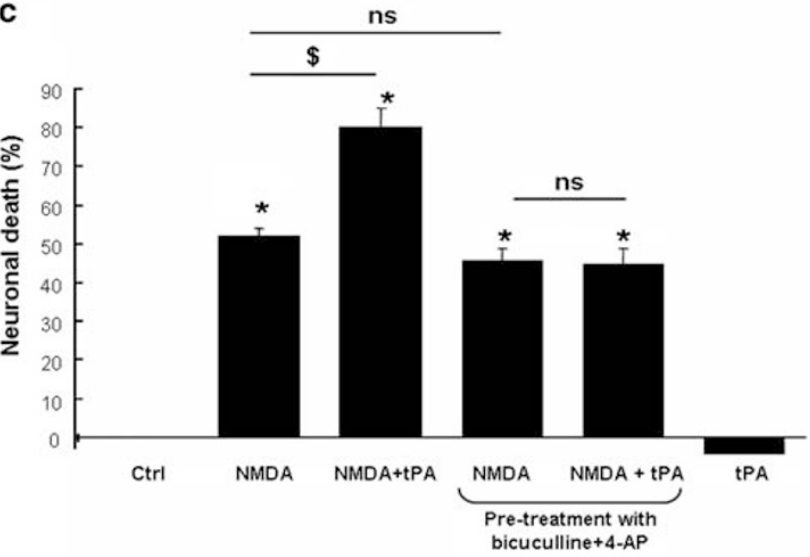

b

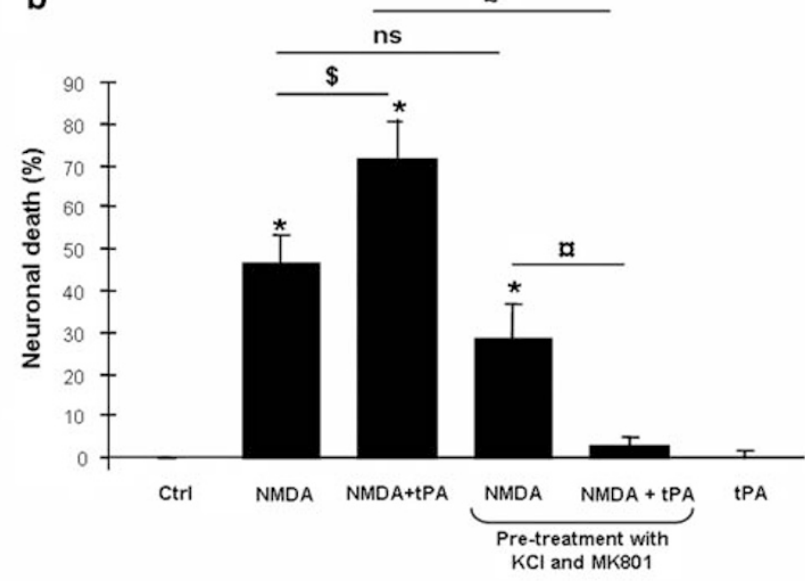

d

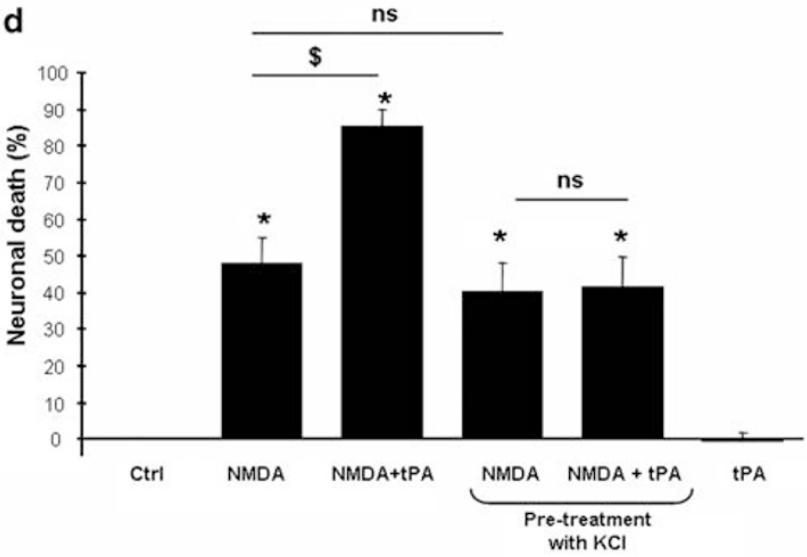

Figure 7 Pre-stimulation of synaptic NMDAR inhibits NMDAR-mediated neurotoxicity promoted by tPA (a, b). Neurons (12-14 DIV) were subjected or not to an incubation in the presence of either bicuculline $(50 \mu \mathrm{M})+4-\mathrm{AP}(2.5 \mathrm{mM})+\mathrm{MK}-801(10 \mu \mathrm{M})(1 \mathrm{~h})(\mathbf{a})$ or KCl $(75 \mathrm{mM})+\mathrm{MK}-801(10 \mu \mathrm{M})(15 \mathrm{~min})$ (b), followed by exposure to NMDA $(50 \mu \mathrm{M})$ alone or in the presence of tPA $(20 \mu \mathrm{g} / \mathrm{ml})$. LDH released into the bathing medium was assessed after $24 \mathrm{~h}$ of treatment. Data are represented as mean \pm S.E.M. $(N=4 ; n=16)$ relative to control $\left(*, \$, \mathrm{f}, \mathbf{a}_{P}<0.05 ;{ }^{*, \ldots \mathfrak{E}} P<0.01\right)$. ${ }^{*}$ Indicates significantly different from control; ${ }^{\$}$ indicates significantly different from NMDA treatment;

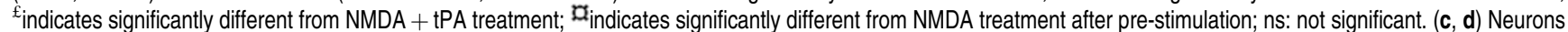
(12-14 DIV) were subjected or not to an incubation in the presence of either bicuculline $(50 \mu \mathrm{M})+4-\mathrm{AP}(2.5 \mathrm{mM})(1 \mathrm{~h})(\mathbf{c})$ or $\mathrm{KCl}(75 \mathrm{mM} ; 15 \mathrm{~min})(\mathrm{d})$ prior NMDA $(50 \mu \mathrm{M})$ exposure alone or in the presence of tPA $(20 \mu \mathrm{g} / \mathrm{ml})$. LDH released into the bathing medium was assessed $24 \mathrm{~h}$ after the excitotoxic exposure. Data are represented as mean \pm S.E.M. $(N=3 ; n=12)$ relative to control $\left({ }^{*, \$} P<0.05\right)$. ${ }^{*}$ ndicates significantly different from control; ${ }^{\$}$ indicates significantly different from NMDA treatment; $n s:$ not significant

of debate. Although it is now well admitted that NR1/NR2A and NR1/NR2B di-heteromeric NMDAR are associated with PSD-95, synapse-associated protein 102 (SAP 102) and PSD-93, ${ }^{28}$ little is known regarding other NMDAR subunits, especially the NR2D subunit. Interestingly, we found that the NR2D subunit is clearly over-expressed in mature cortical neurons in vitro when compared with immature ones. Expression of NR2D subunit was also evidenced in vivo in cortical areas of adult mouse brains, in structures showing positive immunostaining for tPA. Accordingly, we postulated that this subunit could contribute to the pro-neurotoxic effect of tPA. PPDA was reported as a selective NR2D competitive antagonist at low concentrations, as we used, with an IC50 value of around $0.1 \mu \mathrm{M} .^{23,24,29}$ Although, PPDA was also reported as an antagonist of $\mathrm{NR} 2 \mathrm{C}$, in agreement with the absence of NR2C mRNA in our cultured cortical neurons, $\mathrm{N} 2 \mathrm{RC}$ was only detected in the cerebellum, thalamus and olfactory bulb. ${ }^{30}$ At low concentration, PPDA completely prevented the worsening effect of tPA on NMDA-induced neuronal death. Similarly, a neuronal knockdown of NR2D expression blocked the tPA-dependent potentiation of NMDAR-mediated signalling and neurotoxicity. Although the efficiency of transfection in primary cultures of neurons is rather low, our findings using siRNAs are supported by pharmacological approaches (PPDA) and experiments comparing cortical versus hippocampal neurons.

These data are in agreement with recent demonstrations that neurotoxicity is mediated by extra-synaptic NMDAR $^{26}$ and that NR2D subunits of NMDAR are exclusively distributed in extra-synaptic NMDAR. ${ }^{24,31}$ In support of this, we observed a differential sensitivity of cortical versus hippocampal neurons to tPA during excitotoxic conditions that could be explained by the presence and absence, respectively, of the NR2D subunit. Interestingly, the blockage of NMDA-dependent neurotoxicity by a high dose of PPDA disappeared when preceded by pre-synaptic priming. This neuroprotective effect 


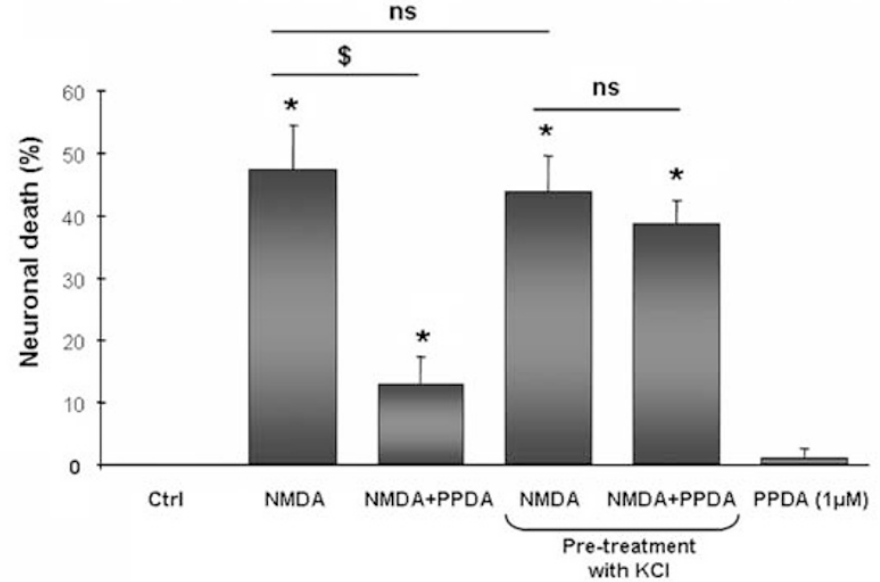

b
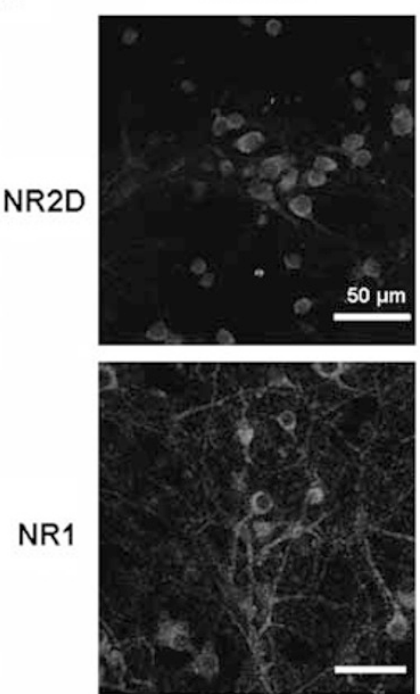
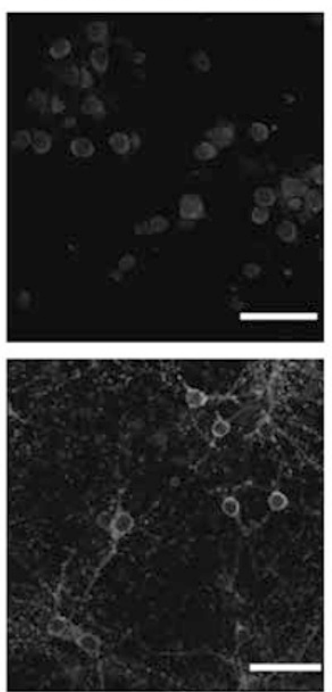

Bicuculline + 4-AP
$\mathrm{KCl}$
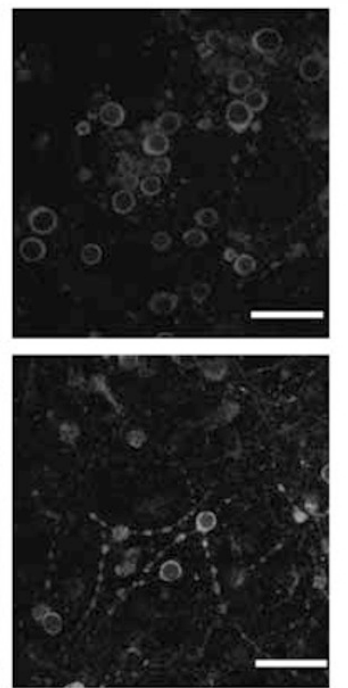

C

NR2D

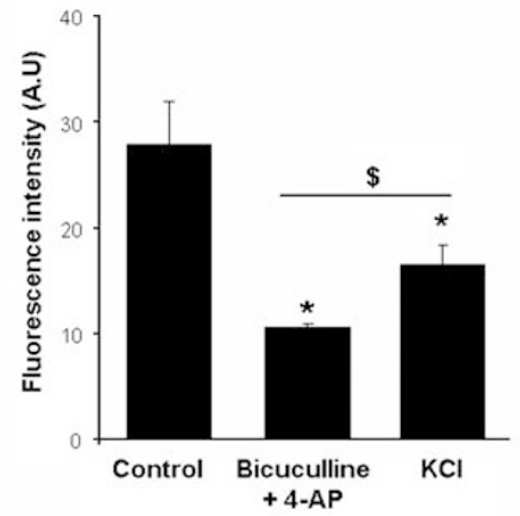

d NR1

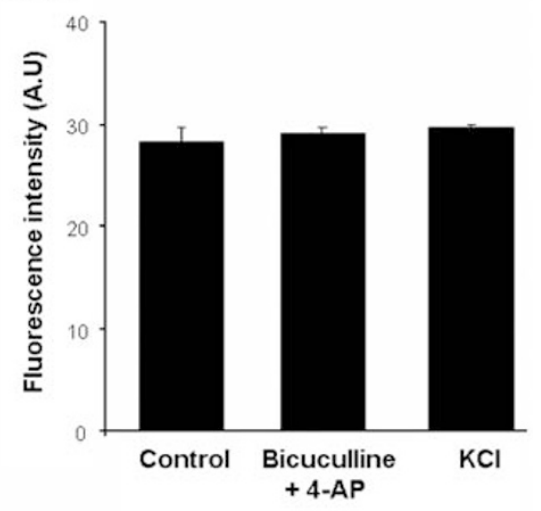

Figure 8 PPDA does not influence NMDA-mediated neurotoxicity after a pre-synaptic priming. (a) Neurons (12-14 DIV) were subjected or not to a 15 min incubation in the presence of $\mathrm{KCl}(75 \mathrm{mM})$, before NMDA $(50 \mu \mathrm{M})$ exposure alone or in the presence of tPA $(20 \mu \mathrm{g} / \mathrm{ml})$ for $60 \mathrm{~min}$. PPDA $(1 \mu \mathrm{M})$ was added concurrently to NMDA to block NR2D-containing NMDAR. LDH released into the bathing medium was assessed $24 \mathrm{~h}$ after the excitotoxic exposure. Data are represented as mean \pm S.E.M. $(N=3 ; n=12)$

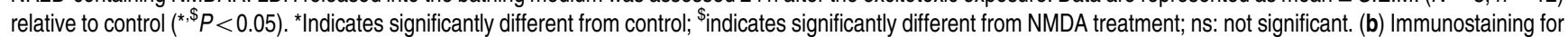
NR2D (red) performed on primary cultures of mouse cortical neurons after $1 \mathrm{~h}$ of bicuculline +4 -AP treatment or $15 \mathrm{~min}$ of $\mathrm{KCl}$ treatment. Scale bars represent $50 \mu \mathrm{m}$. (c) NR2D and (d) NR1 immunostaining were quantified by the application of software Meta Imaging Series 6.3. Values are the mean of $45-60$ cells ( $N=3$ ) (A.U: arbitrary unit). $\left({ }^{*} \$ P<0.05\right)$. *Indicates significantly different from control; $\$$ indicates significantly different from bicuculline +4 -AP treatment (The colour reproduction of this figure is available on the html full text version of the manuscript)

of synaptic pre-stimulation could involve a modification of subunit distribution, in particular of the NR2D subunit. These data are of particular interest and also in agreement with the recent demonstration that extra-synaptic NR2D-containing NMDAR are recruited to the synapse during LTP processes. ${ }^{24}$ It is also interesting to note that IPA was earlier reported to promote LTP. ${ }^{32}$

In addition, we show that priming of synaptic NMDAR signalling prevented both tPA-promoted NMDAR activation of $\operatorname{Erk}\left(\frac{1}{2}\right)$ signalling and subsequent neuronal death. These data could be related to earlier observations that ischemic preconditioning induced either by short exposure to hypoxia or short ischemic episodes could have neuroprotective effects. ${ }^{33}$ Moreover, Tauskela et al. ${ }^{34}$ recently showed that a synaptic NMDAR preconditioning induces a tolerance to oxygen glucose deprivation. Similarly, a protective function of NMDAR in survival of cultured rat cerebellar granule neurons in the presence of depolarizing concentrations of $\mathrm{KCl}$ was earlier proposed. ${ }^{35}$ As this treatment was suggested to mimic endogenous NMDAR-mediated glutamate signalling, it was hypothesized that NMDAR were required for neuronal survival. Indeed, low doses of NMDA pre-treatment were reported to protect neurons against cell death induced by glutamate. ${ }^{25,36}$ Also relevant to this data, increased synaptic activity induced in cortical cultures protects neurons against neurotoxin in an NMDAR-dependent manner ${ }^{26,37}$ Although in the presence of MK-801, tPA reduced neurotoxicity induced by NMDA after a pre-treatment with Bic + 4-AP, it had no 
neuroprotective activity in the absence of MK-801. As MK801 -induced blockage of basal NMDAR signalling was earlier shown to induce apoptotic neuronal death, ${ }^{38}$ we can postulate that in such conditions, tPA could display a neurotrophic activity, which fits well with its earlier shown non-proteolytic anti-apoptotic effect. ${ }^{39}$

In pathological scenarios such as ischemia, $\mathrm{Ca}^{2+}$ influx through the NMDAR is a key mediator of cell death. However, physiological levels of NMDAR activity can promote neuronal survival and resistance to trauma and have important functions in synaptic plasticity and transmission. Here, we show that, although tPA promotes NMDAR-dependent Erk $\left(\frac{1}{2}\right)$ signalling and neurotoxicity, priming induced by synaptic NMDAR stimulation completely prevents these effects of tPA. Interestingly, this data also show that NR2D-containing NMDAR are critical effectors of the tPA-mediated neurotoxicity. Altogether, these insights may lead to better therapeutic strategies that could enable selective blockade of pro-death signalling properties of tPA while sparing physiological signalling to survival and plasticity. These data throw a new light on the mechanism by which tPA (endogenous and exogenous) could influence the outcome after stroke. Indeed, although IPA is the only approved treatment for acute stroke because of its thrombolytic properties, blockage of the excitotoxic neuronal damages produced by tPA is now considered as a challenging strategy to improve the efficiency and/or therapeutic window of stroke acute treatment.

\section{Materials and Methods}

Materials. NMDA, MK801 and PPDA were purchased from Tocris (Bristol, UK). Human ItPA (Actilyse) was purchased from Boehringer Ingelheim (Paris, France). RAP was from Gentaur (Paris, France). tPA-stop was purchased from American Diagnostica (Greenwich, Connecticut). Dulbecco's modified Eagle's medium (DMEM), poly-D-lysine, laminin, glutamine, cytosine $\beta$-D-arabinoside, protease inhibitor cocktail, phosphatase inhibitor cocktail, bicuculline, 4-amimopyridin and U0126 ethanolate were purchased from Sigma-Aldrich (L'Isle d'Abeau, France).

Neuronal cultures. Neuronal cultures were prepared from foetal mice (embryonic day 15-16) as described earlier. ${ }^{40}$ Cortices or hippocampi were dissected and dissociated in DMEM, and plated, respectively, on 24- and 48-well plates earlier coated with poly-D-lysine $(0.1 \mathrm{mg} / \mathrm{ml})$ and laminin $(0.02 \mathrm{mg} / \mathrm{ml})$. Cells were cultured in DMEM supplemented with $5 \%$ fetal bovine serum (Invitrogen, Cergy Pontoise, France), $5 \%$ horse serum (Invitrogen) and $2 \mathrm{mM}$ glutamine. Cultures were maintained at $37^{\circ} \mathrm{C}$ in a humidified $5 \% \mathrm{CO}_{2}$ atmosphere. Cytosine $\beta$ $D$-arabinoside $(10 \mu \mathrm{mol} / /)$ was added after $3 \mathrm{DIV}$ to inhibit glial proliferation. Various treatments were performed after 7 or 12-14 DIV as required.

Assessment of NMDAR-dependent signalling. $\operatorname{Erk}\left(\frac{1}{2}\right)$ activation by phosphorylation was used as an index of NMDAR activity. Synaptic NMDARs were activated by exposure of the primary neuronal cultures to bicuculline $(50 \mu \mathrm{M})$ and 4-AP $(2.5 \mathrm{mM})$ during $1 \mathrm{~h}$. At the indicated times, cells were chilled on ice and lysed in buffer containing Tris-NaCl-Triton $1 \%$ of protease inhibitor cocktail and $1 \%$ of phosphatase inhibitor cocktail. Lysates were clarified by centrifugation at $13000 \times g$ for $10 \mathrm{~min}$ at $4{ }^{\circ} \mathrm{C}$. Proteins were quantified by bicinchonic acid protein assay (Pierce, Thermo Fisher Scientific, Brebières, France) and processed for immunoblotting.

Immunoblotting. Protein samples $(20 \mu \mathrm{g})$ were resolved on a $10 \%$ SDSpolyacryl-amide gel and transferred onto a polyvinylidene difluoride (PVDF) membrane. Membranes were blocked with $5 \%$ dried milk in Tris-buffered saline containing $0.05 \%$ Tween-20 and incubated with primary antibodies (antiphosphorylated Erk $\left(\frac{1}{2}\right)$, d1/1000; Cell Signalling, Ozyme, Saint Quentin en Yvelines, France). After incubation with the corresponding secondary peroxidaseconjugated streptavidine reagent, proteins were visualized with an enhanced chemiluminescence ECL Plus immunoblotting detection system (Perkin ElmerNEN, Paris, France). Total Erk $\left(\frac{1}{2}\right)$ levels (d1/1000; Cell Signalling) were investigated either after stripping of the PVDF membranes used for p-ERK or by running separated immunoblots from the same protein extracts.

Excitotoxic neuronal death. Excitotoxicity was induced by exposure to NMDA $(50 \mu \mathrm{M})$ in serum-free DMEM supplemented with $10 \mu \mathrm{M}$ of glycine (MS-glycine) for $10 \mathrm{~min}$ or $1 \mathrm{~h}$. Wherever mentioned, tPA and inhibitors were coapplied with NMDA. Neuronal death was quantified $24 \mathrm{~h}$ later by measurement of the activity of the lactate dehydrogenase $(\mathrm{LDH})$ released from damaged cells into the bathing medium with a cytotoxicity detection kit (Roche Diagnostics, Mannheim, Germany). The LDH level corresponding to the maximal neuronal death was determined in sister cultures exposed to $200 \mu \mathrm{M}$ NMDA $\left(\mathrm{LDH}_{\max }\right)$. Background LDH levels were determined in sister cultures subjected to control washes $\left(L^{2} H_{\text {min }}\right)$. Experimental values were measured after subtracting $\mathrm{LDH}_{\min }$ and then normalized to $L D H_{\max }-L D H_{\min }$ to express the results in percentage of neuronal death.

Protocol for priming before NMDAR activation. Synaptic NMDAR were activated by exposure of neuronal cultures (14 DIV) to bicuculline $(50 \mu \mathrm{M})$, 4-AP $(2.5 \mathrm{mM})(1 \mathrm{~h})$ or $\mathrm{KCl}(75 \mathrm{mM}, 15 \mathrm{~min})$ and were simultaneous blocked or not by addition of MK-801 $(10 \mu \mathrm{M})$. Then, neurons were washed with MS-glycine (serum-free DMEM supplemented with $10 \mu \mathrm{M}$ of glycine), and after $1 \mathrm{~h}$, NMDAR were activated by exposure to NMDA $(50 \mu \mathrm{M})$.

Extraction of total RNA. Total RNAs were extracted from cultured cells or tissues by using the NucleoSpin RNA II kit from Macherey-Nagel. The samples were lysed in RA1 buffer containing $1 \%$ of $\beta$-mercaptoethanol. After filtration of the lysates on Nucleospin filter units, total RNAs were purified on Nucleospin RNA II columns according to the manufacturer's instructions and eluted with RNasefree water.

Quantitative real-time RT-PCR. One microgram of total RNAs from each sample was reverse transcribed using the Promega RT system (Promega, Charbonnieres, France; reverse transcription: $42^{\circ} \mathrm{C}$ for $1 \mathrm{~h}$ ). Two primers were designed for each gene using the Beacon Designer software (Bio-Rad, Marnes-laCoquette, France). Primer alignments were performed with the BLAST database to ensure the specificity of primers.

$\begin{array}{llll}\text { NMDA1 forward } & \text { CTCTAGCCAGGTCTACGCTATCC NMDA1 reverse } & \text { GACGGGGATTCTGTAGAAGCCA } \\ \text { NMDA2a forward } & \text { ACATCCACGTTCTTCCAGTTTGG } & \text { NMDA2a reverse } & \text { GACATGCCAGTCATAGTCCTGC } \\ \text { NMDA2b forward } & \text { CCAGAGTGAGAGATGGGATTGC } & \text { NMDA2b reverse } & \text { TGGGCTCAGGGATGAAACTGT } \\ \text { NMDA2d forward } & \text { CTGTGTGGGTGATGATGTTCGT } & \text { NMDA2d reverse } & \text { GTGAAGGTAGAGCCTCCGGG } \\ \text { NMDA2c forward } & \text { GGGCTTCTGCATCGACATCC } & \text { NMDA2c reverse } & \text { ATCATACCATTCCACACACCACG } \\ \text { NMDA3a forward } & \text { ATCCTCAAGCGCATCGGACA } & \text { NMDA3a reverse } & \text { CGACTCTGGCTCATCCCTCTG } \\ \text { NMDA3b forward } & \text { GGCCGTGACCAGCTTCAGTA } & \text { NMDA3b reverse } & \text { CAATGGGTGAGGCTGTATCTCG } \\ \text { tPA forward } & \text { CTCCGACCCATGCTCAGAA } & \text { tPA reverse } & \text { TTGTACCAGGCCGCTGTTG } \\ \text { Cyclophyilin forward } & \text { CAGGGTGGTGACTTTACACGC } & \text { Cyclophyilin reverse } & \text { TGTTTGGTCCAGCATTTGCCA }\end{array}$

PCR solutions were prepared with RNase-free water containing primers and IQ SYBR Green Supermix (Bio-Rad). For PCR amplification, $20 \mu \mathrm{l}$ of mix were added to $5 \mu$ l of reverse transcription reaction diluted earlier $(1: 20)$. Two negative controls were performed during each experiment. In the first control, we used samples without reverse transcription as a template to control contamination of RNA with genomic DNA. In the second control, we used RNase-free water instead of CDNA to prove that $\mathrm{qPCR}$ mixes were not contaminated with DNA. Assays were run in triplicate on the iCycler $\mathrm{iQ}$ real-time PCR detection system (Bio-Rad). The amplification conditions were as follows: Hot Goldstar enzyme activation, $95^{\circ} \mathrm{C}$ for $3 \mathrm{~min} ; 50$ cycles of PCR at $95^{\circ} \mathrm{C}, 15 \mathrm{~s}$ and $60^{\circ} \mathrm{C}, 1 \mathrm{~min}$. The levels of expression of interest gene were computed as follows: relative $m R N A$ expression $=2-$ (Ct of gene of interest), where $\mathrm{Ct}$ is the threshold cycle value.

RNA interference. Three Stealth siRNA duplex oligoribonucleotides against NR2D subunits (InVitrogen) were tested. The sequences were as follows: GRIN2D 25 Sense $5^{\prime}$-UGGUAAACCCGUCACUGGUAGUCAU- $3^{\prime}$, Antisense 5'-AUGACUA CCAGUGACGGGUUUACCA-3'; GRIN2D 23 Sense $5^{\prime}$-CCAUCGGUUUCAGCU AUGACCUCUA-3', Antisense 5'-UAGAGGUCAUAGCUGAAACCGAUGG-3'; 
GRIN2D 24 Sense 5'-GCCGUCAUCUUUCUUGCCAGCUAUA-3', Antisense 5'-UA UAGCUGGCAAGAAAGAUGACGGC-3'

siRNA oligos $(40 \mathrm{nM})$ were transfected into primary cortical cultures of neurons maintained 10-11 DIV by using a modified protocol in the presence of Lipofectamine $2000(2 \mu \mathrm{g})$ (InVitrogen). The Stealth RNA negative Control Duplexes (InVitrogen) that is not homologous to any known genes was used as transfection efficiency detector and a negative control to ensure against induction of non-specific cellular events caused by introduction of the oligoribonucleotides into cells. The Stealth siRNA/lipofectamine complexes were applied during $6 \mathrm{~h}$. Cultures were replaced with MS-glycine after the transfection and cells were treated $48 \mathrm{~h}$ later. After characterization by qPCR, among the three siRNA oligo duplexes against NR2D subunit, we selected the one that presents the most significant knockdown effect (GRIN $23 ; 40 \%$ of reduction).

In vivo excitotoxic lesions. Male Swiss mice (20-24 g; CERJ, Paris, France) were housed in a temperature-controlled room on a 12-h light/12-h dark cycle with food and water ad libitum. Experiments were performed in accordance with French ethical laws (act no. 87-848; Ministère de l'Agriculture et de la Forêt) and European Communities Council Directives of 24 November 1986 (86/609/EEC) guidelines for the care and use of laboratory animals. Animals were deeply anesthetized with isoflurane $5 \%$ and, thereafter, maintained with $2.5 \%$ isoflurane in a $70 \% / 30 \%$ mixture of $\mathrm{N}_{2} \mathrm{O} / \mathrm{O}_{2}$. Rectal temperature was maintained at $37 \pm 0.5^{\circ} \mathrm{C}$ throughout the surgical procedure using a feedback-regulated heating system. A catheter was inserted into the tail vein, then excitotoxic lesions were performed. Hippocampal or cortical bilateral injections (coordinates: $-2.3 \mathrm{~mm}$ posterior, $-1.8 \mathrm{~mm}$ lateral, $-1.1 \mathrm{~mm}$ ventral or - coordinates: $0.5 \mathrm{~mm}$ posterior, $\pm 3.0 \mathrm{~mm}$ lateral, $-0.8 \mathrm{~mm}$ ventral to the bregma, respectively) of NMDA (cortex: $2.5 \mathrm{nmoles}$; hippocampus: $5 \mathrm{nmoles}$; total volume of $0.33 \mu \mathrm{l})$ versus phosphate-buffered saline (PBS) (pH 7.4; total volume $0.33 \mu \mathrm{l}$ ) were performed after placing the animals under a stereotaxic frame. Solutions were injected by the use of a micropipette made with hematologic micropipettes (calibrated at $15 \mathrm{~mm} / \mu$ l; assistant ref 555/5; Hecht, Sondheim-Rhoen, Germany). The needle was removed 3 min later. Finally, $200 \mu$ l bolus intravenous injections of tPA $(10 \mathrm{mg} / \mathrm{kg})$ or saline were performed after intracerebral injections.

Histological analysis of lesion volume. After $24 \mathrm{~h}$, mice were anesthetized and transcardially perfused with cold heparinized saline $(15 \mathrm{ml})$ followed by $150 \mathrm{ml}$ of fixative (sodium phosphate buffer $0.1 \mathrm{M}, \mathrm{pH} 7.4$ containing $2 \%$ paraformaldehyde and $0.2 \%$ picric acid). Brains were frequently rinsed in a coons buffer containing $20 \%$ sucrose before freezing in Tissue-Tek (Miles Scientific, Naperville, IL, USA). Cryostat-cut coronal brain sections $(10 \mu \mathrm{m})$ were collected and stained with Fluoro-Jade C. Regions of interest were determined through the use of a stereotaxic atlas for the mouse and an image analysis system (MetaVue software, Molecular Devices, Downingtown, PA, USA) was used to measure the lesioned area. The results are expressed as mean \pm S.E.M.

Immunocytochemistry and immunohistochemistry. Neuronal cultures were prepared on four-well Labtek Chamber-Slide culture system (Thermo Fisher Scientific, Rochester, NY, USA) or glass bottom Petri dishes (MatTek corporation, Ashland, MA, USA) earlier coated with poly-D-lysine $(0.1 \mathrm{mg} /$ $\mathrm{ml}$ ) and laminin $(0.02 \mathrm{mg} / \mathrm{ml})$. Neurons (14 DIV) were fixed during $30 \mathrm{~min}$ with $4 \%$ of paraformaldehyde in PBS $(0.1 \mathrm{M}, \mathrm{pH} 7.4)$. After washes with PBS, they were incubated in the presence of goat polyclonal anti-NR2D or goat polyclonal anti-NR1 (1:500; Santa Cruz Biotechnology, Heidelberg, Germany), before an overnight incubation with the secondary antibody $F\left(a b^{\prime}\right) 2$ fragments of donkey anti-Goat IgG linked to tetramethyl rhodamine isothiocyanate (TRITC) $(1: 300$, Jackson ImmunoResearch, West Grove, PA, USA). Images were digitally captured using a Nikon Eclipse (TE2000-E) inverted C1 confocal microscope equipped with an oil immersion Nikon $\times 60$.objective.

Anesthetized ( $500 \mathrm{mg} / \mathrm{kg}$ of choral hydrate) adult Swiss mice were transcardially perfused with cold heparinized saline $(15 \mathrm{ml})$ followed by $150 \mathrm{ml}$ of fixative (PBS $0.1 \mathrm{M}$. pH 7.4 containing $2 \%$ paraformaldehyde and $0.2 \%$ picric acid). Cryomicrotome-cut sections $(8-12 \mu \mathrm{m})$ were collected and stored at $-80^{\circ} \mathrm{C}$. Sections were incubated in the presence of rabbit polyclonal anti-mouse tPA $(1: 3000$; from Pr. Carmeliet, University of Leuven, Belgium) and goat polyclonal anti-NR2D $(1: 500)$ before an overnight incubation with the secondary antibodies, respectively, $F\left(a b^{\prime}\right) 2$ fragments of donkey anti-rabbit IgG linked to TRITC and $F\left(a b^{\prime}\right) 2$ fragments of donkey anti-Goat IgG linked to FITC (Jackson ImmunoResearch).
LabTek and sections were coverslipped with antifade medium containing DAPI. Images were digitally captured using a Leica DM6000 microscope-coupled coolsnap.

Quantification of immunostaining were performed by using the application software Meta Imaging 6.3.

Statistical analysis. The results are expressed as the mean \pm S.E.M. Statistical analyses were performed by the Kruskall-Wallis' test, followed by post hoc comparisons, with the Mann-Whitney's test.

\section{Conflict of interest}

The authors declare no conflict of interest.

Acknowledgements. We thank Pr Peter Carmeliet for providing us the rabbit polyclonal anti-mouse tPA. We are also grateful to Dr. Alahari for her critical reading of the manuscript. This work was supported by grants from the INSERM and Regional Council of Lower Normandy.

1. Baranes D, Lederfein D, Huang YY, Chen M, Bailey CH, Kandel ER. Tissue plasminogen activator contributes to the late phase of LTP and to synaptic growth in the hippocampal mossy fiber pathway. Neuron 1998; 21: 813-825.

2. Pang PT, Teng HK, Zaitsev E, Woo NT, Sakata K, Zhen $S$ et al. Cleavage of proBDNF by tPA/plasmin is essential for long-term hippocampal plasticity. Science 2004; 306: 487-491.

3. Bruno MA, Cuello AC. Activity-dependent release of precursor nerve growth factor, conversion to mature nerve growth factor, and its degradation by a protease cascade. Proc Natl Acad Sci USA 2006; 103: 6735-6740.

4. Yepes M, Roussel BD, Ali C, Vivien D. Tissue-type plasminogen activator in the ischemic brain: more than a thrombolytic. Trends Neurosci 2009; 32: 48-55.

5. Benchenane K, Berezowski V, Ali C, Fernández-Monreal M, López-Atalaya JP, Brillault J et al. Tissue-type plasminogen activator crosses the intact blood-brain barrier by I ow-density lipoprotein receptor-related protein-mediated transcytosis. Circulation 2005; 111: 2241-2249.

6. Martin AM, Kuhlmann C, Trossbach S, Jaeger S, Waldron E, Roebroek A et al. The functional role of the second NPXY motif of the LRP1 beta-chain in tissue-type plasminogen activator-mediated activation of N-methyl-D-aspartate receptors. J Biol Chem 2008; 283: 12004-12013.

7. Samson AL, Nevin ST, Croucher D, Niego B, Daniel PB, Weiss TW et al. Tissue-type plasminogen activator requires a co-receptor to enhance NMDA receptor function. $J$ Neurochem 2008; 107: 1091-1101.

8. Polavarapu R, Gongora MC, Yi H, Ranganthan S, Lawrence DA, Strickland D et al. Tissuetype plasminogen activator-mediated shedding of astrocytic low-density lipoprotein receptor-related protein increases the permeability of the neurovascular unit. Blood 2007; 109: 3270-3278.

9. Lee HY, Hwang IY, Im H, Koh JY, Kim YH. Non-proteolytic neurotrophic effects of tissue plasminogen activator on cultured mouse cerebrocortical neurons. J Neurochem 2007; 101: $1236-1247$.

10. Nicole O, Docagne F, Ali C, Margaill I, Carmeliet P, Mackenzie ET et al. The proteolytic activity of tissue-plasminogen activator enhances NMDA receptor-mediated signaling. Nat Med 2001; 7: 59-64.

11. Fernández-Monreal M, López-Atalaya JP, Benchenane K, Cacquevel M, Dulin F, Le Caer JP et al. Arginine 260 of the amino-terminal domain of NR1 subunit is critical for tissue-type plasminogen activator-mediated enhancement of $\mathrm{N}$-methyl-D-aspartate receptor signaling. $J$ Biol Chem 2004; 279: 50850-50856.

12. Benchenane K, Castel H, Boulouard M, Bluthé R, Fernandez-Monreal M, Roussel BD et al. Anti-NR1 N-terminal-domain vaccination unmasks the crucial action of TPA on NMDAreceptor-mediated toxicity and spatial memory. J Cell Sci 2007; 120: 578-585.

13. Pawlak R, Melchor JP, Matys T, Skrzypiec AE, Strickland S. Ethanol-withdrawal seizures are controlled by tissue plasminogen activator via modulation of NR2B-containing NMDA receptors. Proc Natl Acad Sci USA 2005; 102: 443-448.

14. Norris EH, Strickland S. Modulation of NR2B-regulated contextual fear in the hippocampus by the tissue plasminogen activator system. Proc Natl Acad Sci USA 2007; 104: 13473-13478.

15. Medina MG, Ledesma MD, Domínguez JE, Medina M, Zafra D, Alameda F et al. Tissue plasminogen activator mediates amyloid-induced neurotoxicity via Erk1/2 activation. EMBO J 2005; 24: 1706-1716.

16. Samson AL, Medcalf RL. Tissue-type plasminogen activator: a multifaceted modulator of neurotransmission and synaptic plasticity. Neuron 2006; 50: 673-678.

17. Thomas GM, Huganir RL. MAPK cascade signalling and synaptic plasticity. Nat Rev Neurosci 2004; 5: 173-183.

18. Gardoni F, Di Luca M. New targets for pharmacological intervention in the glutamatergic synapse. Eur J Pharmacol 2006; 545: 2-10. 
19. Lau CG, Zukin RS. NMDA receptor trafficking in synaptic plasticity and neuropsychiatric disorders. Nat Rev Neurosci 2007; 8: 413-426.

20. Cull-Candy SG, Leszkiewicz DN. Role of distinct NMDA receptor subtypes at central synapses. Sci STKE 2004; 2004: re16.

21. Papadia S, Hardingham GE. The dichotomy of NMDA receptor signaling. Neuroscientist 2007; 13: 572-579.

22. Kohr G. NMDA receptor function: subunit composition versus spatial distribution. Cell Tissue Res 2006; 326: 439-446.

23. Feng B, Tse HW, Skifter DA, Morley R, Jane DE, Monaghan DT. Structure-activity analysis of a novel NR2C/NR2D-preferring NMDA receptor antagonist: 1-(phenanthrene-2carbonyl) piperazine-2,3-dicarboxylic acid. Br J Pharmacol 2004; 141: 508-516.

24. Harney SC, Jane DE, Anwyl R. Extrasynaptic NR2D-containing NMDARs are recruited to the synapse during LTP of NMDAR-EPSCs. J Neurosci 2008; 28: 11685-11694.

25. Soriano FX, Papadia S, Hofmann F, Hardingham NR, Bading H, Hardingham GE. Preconditioning doses of NMDA promote neuroprotection by enhancing neuronal excitability. J Neurosci 2006; 26: 4509-4518.

26. Hardingham GE, Fukunaga $Y$, Bading $H$. Extrasynaptic NMDARs oppose synaptic NMDARs by triggering CREB shut-off and cell death pathways. Nat Neurosci 2002; 5 405-414, Comment in: Nat Neurosci 2002; 5: 389-390.

27. Liu Y, Wong TP, Aarts M, Rooyakkers A, Liu L, Lai TW et al. NMDA receptor subunits have differential roles in mediating excitotoxic neuronal death both in vitro and in vivo. J Neurosci 2007; 27: 2846-2857.

28. Al-Hallaq RA, Conrads TP, Veenstra TD, Wenthold RJ. NMDA di-heteromeric receptor populations and associated proteins in rat hippocampus. J Neurosci 2007; 27: 8334-8343.

29. Hrabetova S, Serrano P, Blace N, Tse HW, Skifter DA, Jane DE et al. Distinct NMDA receptor subpopulations contribute to long-term potentiation and long-term depression induction. J Neurosci 2000; 20: RC81.

30. Wenzel A, Fritschy JM, Mohler H, Benke D. NMDA receptor heterogeneity during postnatal development of the rat brain: differential expression of the NR2A, NR2B, and NR2C subunit proteins. J Neurochem 1997; 68: 469-478.
31. Brickley SG, Misra C, Mok MH, Mishina M, Cull-Candy SG. NR2B and NR2D subunits coassemble in cerebellar Golgi cells to form a distinct NMDA receptor subtype restricted to extrasynaptic sites. J Neurosci 2003; 23: 4958-4966.

32. Pang PT, Teng HK, Zaitsev E, Woo NT, Sakata K, Zhen S et al. Cleavage of proBDNF by tPA/plasmin is essential for long-term hippocampal plasticity. Science 2004; 306: 487-491.

33. Zhang J, Qian H, Zhao P, Hong SS, Xia Y. Rapid hypoxia preconditioning protects cortical neurons from glutamate toxicity through delta-opioid receptor. Stroke 2006; 37: 1094-1099.

34. Tauskela JS, Fang H, Hewitt M, Brunette E, Ahuja T, Thiverge JP et al. Elevated synaptic activity preconditions neurons against an in vitro model of ischemia. J Biol Chem 2008; 283: 34667-34676.

35. Yan GM, Ni B, Weller M, Wood KA, Paul SM. Depolarization or glutamate receptor activation blocks apoptotic cell death of cultured cerebellar granule neurons. Brain Res 1994; 656: 43-51.

36. Marini AM, Paul SM. N-methyl-D-aspartate receptor-mediated neuroprotection in cerebellar granule cells requires new RNA and protein synthesis. Proc Natl Acad Sci USA 1992; 89: 6555-6559.

37. Papadia S, Stevenson P, Hardingham NR, Bading H, Hardingham GE. Nuclear Ca2+ and the cAMP response element-binding protein family mediate a late phase of activitydependent neuroprotection. J Neurosci 2005; 25: 4279-4287.

38. Terro F, Esclaire F, Yardin C, Hugon J. N-methyl-D-aspartate receptor blockade enhances neuronal apoptosis induced by serum deprivation. Neurosci Lett 2000; 278: 149-152.

39. Liot G, Roussel BD, Lebeurrier N, Benchenane K, López-Atalaya JP, Vivien D et al. Tissue-type plasminogen activator rescues neurones from serum deprivation-induced apoptosis through a mechanism independent of its proteolytic activity. J Neurochem 2006; 98: $1458-1464$.

40. Rose K, Goldberg MP, Choi DW. Cytotoxicity in murine cortical cell culture In: Tyson CA, Frazier JM (eds). In Vitro Biological Methods. Academic Press: San Diego, California, USA, 1993.

\section{Supplementary Information accompanies the paper on Cell Death and Differentiation website (http://www.nature.com/cdd)}

